\title{
Some mathematical comments about the Analytic Hierarchy Process: Part II - Practical analysis
}

\author{
Rafael Guimarães de Almeida ${ }^{1}$ (D), Gustavo Benitez Alvarez ${ }^{1,2}$ (D), Cecília \\ Toledo Hernández ${ }^{1,3}$ (D) \& Patrícia Alves Pereira de Sousa ${ }^{2}$ (D)
}

(1) Fluminense Federal University, Post-Graduate Program in Computational Modeling in Science and Technology, Avenida dos Trabalhadores 420, Vila Santa Cecília 27255-125, Volta Redonda, Rio de Janeiro, Brazil. E-mail: rafael_almeida@id.uff.br

(2) Fluminense Federal University, Department of Exact Sciences, Avenida dos Trabalhadores 420, Vila Santa Cecília 27255-125, Volta Redonda, Rio de Janeiro, Brazil.

E-mail: benitez.gustavo@gmail.com, papsousa@gmail.com

(3) Fluminense Federal University, Department of Production Engineering, Avenida dos Trabalhadores 420, Vila Santa Cecília 27255-125, Volta Redonda, Rio de Janeiro, Brazil. E-mail: ctoledo@id.uff.br

Almeida R.G., Alvarez G.B., Hernández C.T. \& Sousa P.A.P. (2021) Alguns comentários matemáticos sobre o Analytic Hierarchy Process: Parte II - Análise prática. Pesquisa e Ensino em Ciências Exatas e da Natureza, 5: e1820. http://dx.doi.org/10.29215/pecen.v5i0.1820

Academic editor: Claudia Mazza Dias. Received: 08 July 2021. Accepted: 30 August 2021. Published: 30 November 2021.

Alguns comentários matemáticos sobre o Analytic Hierarchy Process: Parte II - Análise prática

Resumo: O Analytic Hierarchy Process (AHP) é um método de apoio à decisão tendo como uma das maiores críticas o efeito de reversão de ranking. Uma nova análise matemática deste método é realizada em 22 aplicações. Duas formulações do AHP mostram-se equivalentes em solução e comportamento na análise de sensibilidade. A análise de sensibilidade realizada inclui uma parte típica usando o elemento crítico e duas novas análises usando o vetor coluna crítica e o número de condicionamento. Em alguns casos, o AHP é mais sensível a perturbações no vetor coluna crítico do que a perturbações no elemento crítico. $\mathrm{O}$ vetor coluna crítico é único, independentemente da perturbação ser relativa ou absoluta. A análise de sensibilidade usando o número de condicionamento revela que a reversão de ranking sempre existirá para todo método linear. Transformações algébricas para matrizes com posto incompleto são realizadas para obter um método mais estável e confiável.

Palavras chave: Análise múltiple critérios, análise de decisão, reversão de ranking, sistemas lineares de equações, análise de sensibilidade, tomada de decisão.

Abstract: The Analytic Hierarchy Process (AHP) is a decision making method, which has as its greatest criticism the rank reversal effect. A new mathematical analysis of this method is performed in 22 applications. Two formulations of the AHP show to be equivalent in solution and behavior in the sensitivity analysis. The sensitivity analysis carried out includes a standard part using the critical element, and two new analyzes using the critical column vector and condition number. In some cases, AHP is more sensitive to perturbations in the critical column vector than to perturbations in the critical element. The critical column vector is unique independently of whether the perturbation is relative or absolute. The sensitivity analysis using the condition number reveals that the rank reversal will always exist for every linear method. Algebraic transformations for deficient rank matrix are performed to obtain a more stable and reliable method.

Key words: Multiple criteria analysis, decision analysis, rank reversal, linear systems of equations, sensitivity analysis, decision making. 


\section{Introdução}

The Analytic Hierarchy Process (AHP) is a widely used decision making method. The method consists of four steps: Modeling, Valuation, Prioritization and Synthesis. Since its inception, the AHP has been the target of some criticism. The effect called rank reversal is one of the criticisms associated with the results synthesis procedure, which is related to the sensitivity analysis and greatly impacts the reliability and robustness of the method. For reasons of space, the research was divided into two parts. In Part I (Alvarez et al. 2021), the Synthesis of the AHP is formulated in terms of a linear system of equations. In this way it is possible to develop a theoretical basis for the new mathematical analysis of the method. This Part II is the continuation of the research, in which the theoretical basis is applied to 22 practical cases of AHP. The main objective of this work is to put into practice the theoretical development carried out in Part I. That is, the classical formulation of the AHP will be confronted with equivalent formulations. This comparison will be made with sensitivity analysis that allows delimiting the region where the rank reversal effect occurs. Furthermore, through an example it is shown that algebraic transformations to condense the deficient rank matrices add greater stability to the solution of the AHP. Thus, the decision made with the help of the AHP becomes more reliable and robust. Therefore, to save space here an introduction with bibliographic revision as usual is not presented. The Introduction with the entire literature review on the topic presented in Alvarez et al. (2021) is completely applicable in this part of the research, as Part II is a continuation of Part I.

The notation used will be the same as shown in Alvarez et al. (2021). That is, the notation used will be bold capital letter for matrices $\left(\mathbf{G}_{A \times C}\right)$ and vectors $\left(\mathbf{B}_{C \times 1}\right)$. To avoid misunderstandings the dimensions are explicitly given in the sub-index. Bold lowercase letters denote the matrix entries $\left(\mathbf{g}_{i j}\right)$ and vector components $\left(\mathbf{b}_{i}\right)$.

This Part II is organized as follows. Mathematical formulations and applications of the AHP are presented in next Section. The following Section presents standard and a new sensitivity analysis of the method. Posteriorly, algebraic transformations for deficient rank matrix are introduced. Interesting comments about the rank reversal effect are presented in next Section. Finally, the last Section contains some conclusions.

\section{Mathematical formulations and applications of the AHP}

The new mathematical analysis of the AHP is focused only on the Synthesis step (Alvarez et al. 2021). This analysis can be applied to any decision-making methods based on matrices and linear systems of equations whose synthesis can be formulated as equation (1). Suppose $C$ criteria with $A$ alternatives, let $\mathbf{B}_{C \times 1}$ be the criteria priority vector, let $\mathbf{G}_{A x C}$ be the matrix whose columns correspond to the priorities of the alternative with respect to each criterion, and let $\mathbf{X}_{A \times 1}$ be the overall priorities for the alternatives. As presented in Alvarez et al. (2021), there are two formulations for AHP. First, the original formulation given by the equation (1). Second, the equivalent formulation given by the equation (2). In Alvarez et al. (2021) two appropriate choices for $\mathbf{C}_{C \times A}$ were described by equations (3) and (4), where the superscript [o] $]^{T}$ denote the transpose of a vector or matrix, that is $\left[\mathbf{G}_{A x C}\right]^{T}=\mathbf{G}_{C \times A}^{T}$.

$$
\begin{aligned}
& \mathbf{X}_{A \times 1}^{O R G}=\mathbf{G}_{A \times C} \mathbf{B}_{C \times 1} . \\
& \mathbf{C}_{C \times A} \mathbf{X}_{A \times 1}^{E Q V}=\mathbf{C}_{C \times A} \mathbf{G}_{A \times C} \mathbf{B}_{C \times 1} \equiv \mathbf{D}_{C \times 1} .
\end{aligned}
$$

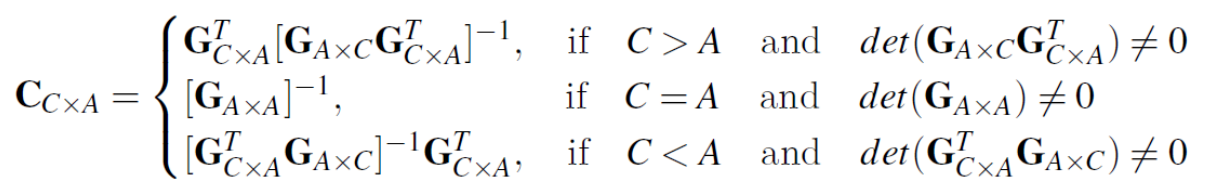




$$
\mathbf{C}_{C \times A}=\mathbf{G}_{C \times A}^{T} .
$$

Thus, to confront the formulations, the following solutions will be considered: $\mathbf{X}_{A \mathrm{x} 1}^{O R G}$, $\mathbf{X}_{A \mathrm{x} 1}^{E Q V 1}, \mathbf{X}_{A \mathrm{x} 1}^{E Q V 2}$ and $\mathbf{X}_{A \mathrm{x} 1}^{E Q V 3} \cdot \mathbf{X}_{A \mathrm{x} 1}^{E Q V 1}$ denotes the solution of the equivalent formulation for $\mathbf{C}_{C \mathrm{x} A}$ given by the equation (3), and $\mathbf{X}_{A \times 1}^{E Q V 2}$ corresponds to the solution of (2) for the choice (4). The computational algorithms to calculate the solutions were implemented in the MATLAB ${ }^{\circledR}$ software. For the solutions $\mathbf{X}_{A \times 1}^{E Q V 1}$ and $\mathbf{X}_{A \times 1}^{E Q V 2}$ the MATLAB ${ }^{\circledR}$ 's backslash command was used, which uses different numerical methods according to the matrix properties of the linear system. The solution $\mathbf{X}_{A \times 1}^{E Q V 3}$ corresponds to the equivalent formulation for the choice (4) using the MATLAB's ${ }^{\circledR i n v}(\mathbf{o})$ function. This function returns the pseudo-inverse of $\mathbf{C}_{C \mathrm{X} A}$ using SVD decomposition. Further details of MATLAB's functions can be found in Yang et al. (2005) and Moler (2008).

For case analysis, 22 applications of the AHP found in the literature were chosen considering two restrictions. First, applications whose Synthesis process was carried out through additive aggregation. Second, applications in which the columns of $\mathbf{G}_{A \times C}$ and $\mathbf{B}_{C \times 1}$ were formed by normalized eigenvectors. From these applications, the matrix $\mathbf{G}_{A x C}$ and the vector $\mathbf{B}_{C \times 1}$ were extracted as input data for the calculations.

Table 1 shows some peculiarities of the 22 applications of AHP analyzed. The first column corresponds to the reference of the application case. In the second and third columns the dimensions of $\mathbf{G}_{A x C}$ and $K \equiv \operatorname{rank}\left(\mathbf{G}_{A x C}\right)$ are shown, respectively. Note that when $K<\min \{C, A\}$ the matrix is rank deficient, and one application check this condition (Koksal \& Ozmutaf 2009). The fourth column shows whether the system corresponding to the equivalent formulation is square (sqr), overdetermined (ovt) or underdetermined (udt). In all overdetermined cases $(C>A)$ the system is consistent. This is, the vector $\mathbf{D}_{C \times 1}$ is a linear combination of the columns of $\mathbf{C}_{C \times A}$, and as $\mathbf{C}_{C \times A}$ is full rank then the system has a unique solution. In all underdetermined cases $(C<$ $A$ ) the linear system has infinite solutions, but the particular choices (3) and (4) for $\mathbf{C}_{C \times A}$ make the solution $\mathbf{X}_{A \mathrm{x} 1}^{E Q V}=\mathbf{X}_{A \mathrm{x} 1}^{O R G}$. The fifth and sixth columns have the smallest angle between the row or column vectors of $\mathbf{G}_{A x C}$, where the index $i$ and $j$ represent the respective rows or columns (Alvarez et al. 2021). Similarly, the seventh and eighth columns correspond to the smallest angle between the row or column vectors of $\mathbf{C}_{C \times A}$ for the choice given by the equation (3). If $\mathbf{C}_{C \times A}=$ $\mathbf{G}_{C \mathrm{X} A}^{T}$ the angles coincide with those of $\mathbf{G}_{A \mathrm{x} C}$ by exchanging rows for columns.

In addition, it should be mentioned that the solutions $\mathbf{X}_{A \times 1}^{E Q V}$ may differ depending on the numerical method used to solve the linear system. Mathematical and computational details on numerical methods for the linear system can be found in Strang (1988), Demmel (1997), Lee (2012), Gentle (2007), Quarteroni \& Saleri (2007) and Golub \& Van Loan (2013). However, in all cases of application $\mathbf{X}_{A \times 1}^{E Q V 1}=\mathbf{X}_{A \times 1}^{E Q V 2}=\mathbf{X}_{A \times 1}^{E Q V 3}=\mathbf{X}_{A \times 1}^{O R G}$.

An important aspect to highlight in Table $\mathbf{1}$ is about deficient rank as mentioned in Alvarez et al. (2021). Angles equal to zero were highlighted in bold, indicating that there are parallel rows or columns. In the case of Koksal \& Ozmutaf (2009), the equivalent formulation with the choice $\mathbf{C}_{C \times A}=\mathbf{G}_{C \times A}^{T}$ shows ${ }_{G}^{c l} \theta_{13}^{\min }=0$. That is, the hyperplanes corresponding to rows 1 and 3 of $\mathbf{G}_{C \times A}^{T}$ are parallel, and this is the cause of the deficient rank. In the cases of Cabała (2010), Gomede \& Barros (2012) and Franco et al. (2017), the zero angles do not cause deficient rank because they are present in the largest dimension of $\mathbf{G}_{A \times C}$ or $\mathbf{C}_{C \times A}$. In the case of Gomede \& Barros (2012), the zero angle is present six times in the largest dimension of $\mathbf{G}_{A \times C}$ or $\mathbf{C}_{C \times A}$. That is, three columns of $\mathbf{G}_{A \times C}$ are equal $\left(\mathbf{Z}_{4 \times 1}^{2}=\mathbf{Z}_{4 \times 1}^{3}=\mathbf{Z}_{4 \times 1}^{4}\right)$, and also other four columns of $\mathbf{G}_{A \times C}$ are equal $\left(\mathbf{Z}_{4 \times 1}^{6}=\mathbf{Z}_{4 \times 1}^{7}=\mathbf{Z}_{4 \times 1}^{8}=\mathbf{Z}_{4 \times 1}^{9}\right)$.

Another important aspect to highlight in Table $\mathbf{1}$ is about almost deficient rank as mentioned in Alvarez et al. (2021). For example, angles less than $2^{\circ}$ have been highlighted by underlining. These small angles indicate that there are almost parallel rows or columns, which can become parallel due to rounding/truncation errors in the calculations (Alvarez et al. 2021). The cases of Gomede \& Barros (2012) and Giri \& Nejadhashemi (2014) are examples of almost deficient rank. In the cases of Al-Harbi (2001), de Abreu et al. (2000), de Paula \& Mello (2013) 
and Benítez et al. (2019), these small angles cannot motivate almost deficient rank because they are present in the largest dimension of $\mathbf{G}_{A x C}$ or $\mathbf{C}_{C \times A}$. Other details can be found in de Almeida (2019).

Table 1. AHP application cases.

\begin{tabular}{|c|c|c|c|c|c|c|c|}
\hline Case & $\mathbf{J}_{A \times C}$ & $K$ & $\mathrm{EF}$ & ${ }_{\mathbf{G}}^{\mathrm{rW}} \theta_{i j}^{\min }, i, j$ & ${ }_{\mathbf{G}}^{\mathrm{c}} \theta_{i j}^{\min }, i, j$ & $\mathrm{CW}^{\mathrm{rw}} \theta_{i j}^{\min }, i, j$ & ${ }_{\mathbf{C}}^{\mathrm{cl}} \theta_{i j}^{\min }, i, j$ \\
\hline 1 & $\mathbf{G}_{3 \times 3}$ & 3 & sqr & $19.1^{\circ}, 2,3$ & $18.8^{\circ}, 1,3$ & $60.6^{\circ}, 1,2$ & $84.4^{\circ}, 1,3$ \\
\hline 2 & $\mathbf{G}_{5 \times 5}$ & 5 & sqr & $30.7^{\circ}, 1,3$ & $26.4^{\circ}, 3,4$ & $14.8^{\circ}, 4,5$ & $47.8^{\circ}, 2,3$ \\
\hline 3 & $5 \times 5$ & 5 & sqr & $6.4^{\circ}, 3,5$ & $1.4^{\circ}, 3,4$ & $14.6^{\circ}, 1,3$ & $8.4^{\circ}, 1,5$ \\
\hline 4 & $\mathbf{G}_{5 \times 5}$ & 5 & sqr & $17.8^{\circ}, 2,3$ & $\overline{11.9^{\circ}, 1,2}$ & $11.3^{\circ}, 2,3$ & $18.2^{\circ}, 1,4$ \\
\hline 5 & $\mathbf{G}_{6 \times 3}$ & 3 & $\mathrm{udt}$ & $1.4^{\circ}, 3,4$ & $3.5^{\circ}, 1,3$ & $57.2^{\circ}, 2,3$ & $1.1^{\circ}, 3,4$ \\
\hline 6 & $\mathbf{G}_{6 \times 4}$ & 4 & $\mathrm{udt}$ & $14.8^{\circ}, 3,4$ & $33.1^{\circ}, 2,4$ & $78.6^{\circ}, 1,4$ & $29.7^{\circ}, 2,6$ \\
\hline 7 & $\mathbf{G}_{6 \times 5}$ & 5 & $\mathrm{udt}$ & $20.2^{\circ}, 2,4$ & $25.5^{\circ}, 3,5$ & $61.2^{\circ}, 2,4$ & $47.7^{\circ}, 2,4$ \\
\hline 8 & $\mathbf{G}_{6 \times 5}$ & 4 & udt & $15.5^{\circ}, 3,4$ & $0.0^{\circ}, 1,3$ & $13.5^{\circ}, 1,5$ & $8.7^{\circ}, 1,5$ \\
\hline 9 & $\mathbf{G}_{6 \times 5}$ & 5 & $\mathrm{udt}$ & $8.9^{\circ}, 4,5$ & $13.6^{\circ}, 2,5$ & $50.6^{\circ}, 2,3$ & $2.5^{\circ}, 4,5$ \\
\hline 10 & $\mathbf{G}_{7 \times 3}$ & 3 & $\mathrm{udt}$ & $6.2^{\circ}, 4,7$ & $29.6^{\circ}, 1,3$ & $103.4^{\circ}, 1,2$ & $16.1^{\circ}, 1,6$ \\
\hline 11 & $\mathbf{G}_{7 \times 6}$ & 6 & $\mathrm{udt}$ & $2.3^{\circ}, 6,7$ & $4.5^{\circ}, 1,3$ & $30.3^{\circ}, 1,4$ & $9.2^{\circ}, 2,3$ \\
\hline 12 & $\mathbf{G}_{2 \times 5}$ & 2 & ovt & $73.7^{\circ}, 1,2$ & $0.0^{\circ}, \mathbf{3}, 5$ & $0.0^{\circ}, \mathbf{3}, 5$ & $106.3^{\circ}, 1,2$ \\
\hline 13 & $\mathbf{G}_{3 \times 5}$ & 3 & ovt & $50.1^{\circ}, 2,3$ & $0.5^{\circ}, 1,2$ & $0.5^{\circ}, 1,2$ & $88.7^{\circ}, 1,3$ \\
\hline 14 & $\mathbf{G}_{3 \times 5}$ & 3 & ovt & $36.1^{\circ}, 2,3$ & $1.9^{\circ}, 2,4$ & $9.0^{\circ}, 1,3$ & $55.0^{\circ}, 1,3$ \\
\hline 15 & $\mathbf{G}_{3 \times 7}$ & 3 & ovt & $41.7^{\circ}, 1,3$ & $7.0^{\circ}, 2,6$ & $15.1^{\circ}, 2,6$ & $108.2^{\circ}, 2,3$ \\
\hline 16 & $\mathbf{G}_{3 \times 7}$ & 3 & ovt & $54.8^{\circ}, 1,2$ & $0.0^{\circ}, 3,5$ & $0.0^{\circ}, 3,5$ & $95.9^{\circ}, 2,3$ \\
\hline 17 & $\mathbf{G}_{4 \times 5}$ & 4 & ovt & $26.2^{\circ}, 3,4$ & $9.2^{\circ}, 1,2$ & $13.9^{\circ}, 1,4$ & $42.6^{\circ}, 1,2$ \\
\hline 18 & $\mathbf{G}_{4 \times 6}$ & 4 & ovt & $25.1^{\circ}, 2,3$ & $4.1^{\circ}, 3,6$ & $9.8^{\circ}, 5,6$ & $50.5^{\circ}, 2,4$ \\
\hline 19 & $\mathbf{G}_{4 \times 9}$ & 4 & ovt & $1.4^{\circ}, 2,4$ & $\begin{array}{c}0.0^{\circ}, 2,3,4 \\
0.0^{\circ}, 6,7,8,9\end{array}$ & $\begin{array}{c}0.0^{\circ}, 2,3,4 \\
0.0^{\circ}, 6,7,8,9\end{array}$ & $61.8^{\circ}, 1,2$ \\
\hline 20 & & 5 & ovt & $21.6^{\circ}, 2,5$ & $10.5^{\circ}, 4,5$ & $1.2^{\circ}, 3,5$ & $11.1^{\circ}, 2,4$ \\
\hline 21 & & 5 & ovt & $36.7^{\circ}, 3,5$ & $25.8^{\circ}, 3,4$ & $47.6^{\circ}, 3,4$ & $84.3^{\circ}, 2,5$ \\
\hline 22 & $\mathbf{G}_{5 \times 9}$ & 5 & ovt & $21.7^{\circ}, 4,5$ & $8.6^{\circ}, 4,8$ & $9.9^{\circ}, 5,7$ & $61.4^{\circ}, 2,3$ \\
\hline
\end{tabular}

\section{Sensitivity analysis of the AHP}

As presented in Alvarez et al. (2021), changes or errors in $\mathbf{B}_{C \times 1}$ and/or $\mathbf{G}_{A x C}$ imply changes in $\mathbf{X}_{A \times 1}^{O R G}$ and $\mathbf{X}_{A \times 1}^{E Q V}$. It is important to note that there are two types of errors in this analysis. First, uncertainties in the construction of $\mathbf{B}_{A \times 1}$ and/or $\mathbf{G}_{A \times A}$. Second, inaccuracies by the round-off errors when performing calculations due to computer finite precision arithmetic. These changes or errors can be estimated via sensitivity analysis. Here two sensitivity analyzes are presented. First, the typical sensitivity analysis in the context of the AHP, where only one entry of $\mathbf{G}_{A x C}$ or $\mathbf{B}_{C \times 1}$ is perturbed, which are called critical element of $\mathbf{G}_{A \times C}$ and critical criterion of $\mathbf{B}_{C \times 1}$, respectively (Triantaphyllou \& Sánchez 1997; Pankratova \& Nedashkovskaya 2016). Second, a new sensitivity analysis in the context of the AHP, where one column vectors of $\mathbf{G}_{A x C}$ is perturbed, which will be called critical column vector (Alvarez et al. 2021).

\section{Typical sensitivity analysis of the AHP}

This sensitivity analysis is based on the ideas presented in Triantaphyllou \& Sánchez (1997), where the minimum relative/absolute perturbations are determined in a single element of $\mathbf{B}_{C \times 1}$ or $\mathbf{G}_{A \times C}$ that cause any change in ranking of $\mathbf{X}_{A \times 1}^{O R G}$ and $\mathbf{X}_{A \times 1}^{E Q V}$. However, to determine the minimum relative/absolute perturbations and the most sensitive elements, a computational code 
in MATLAB $^{\circledast}$ was developed following the Algorithm 1. This algorithm is based on the idea of seeking the minimum perturbation, scanning element by element, but considering a range of viable perturbations and an update in the data. The validation of this code was performed with Pankratova \& Nedashkovskaya (2016), which in essence is a generalization of the methodology proposed in Triantaphyllou \& Sánchez (1997). In addition, the results of this standard sensitivity analysis are in agreement with the results of the SuperDecisions software.

Considering the Definition 1 in Alvarez et al. (2021) the following notation will be used. The minimum relative and absolute perturbations in $\mathbf{G}_{A x C}$ are $\Delta \mathrm{g}_{i j}^{r l t}$ and $\Delta \mathrm{g}_{i j}^{a b s}$, respectively. The critical element obtained via $\Delta \mathrm{g}_{i j}^{r l t}$ is $\mathrm{g}_{i j}^{r l t}$, and the critical element obtained via $\Delta \mathrm{g}_{i j}^{a b s}$ is $\mathrm{g}_{i j}^{a b s}$. The smallest and largest magnitude entries for $\mathbf{G}_{A x C}$ are $\mathbf{g}_{i j}^{\min }$ and $\mathbf{g}_{i j}^{\max }$, respectively. Similarly, the minimum relative and absolute perturbations in $\mathbf{B}_{C \times 1}$ are $\Delta \mathbf{b}_{j}^{r l t}$ and $\Delta \mathbf{b}_{j}^{a b s}$, respectively. The critical element obtained via $\Delta \mathbf{b}_{j}^{r l t}$ is $\mathbf{b}_{j}^{r l t}$, and the critical element obtained via $\Delta \mathbf{b}_{j}^{a b s}$ is $\mathbf{b}_{j}^{a b s}$. The smallest and largest magnitude entries for $\mathbf{B}_{C \times 1}$ are $\mathbf{b}_{j}^{\min }$ and $\mathbf{b}_{j}^{\max }$, respectively. Considering $\delta=$ $10^{-6}$ in the Algorithm 1 the minimum perturbations and the critical elements for each case of application of the AHP were determined. The results are shown in Figures $\mathbf{1}$ and $\mathbf{2}$.
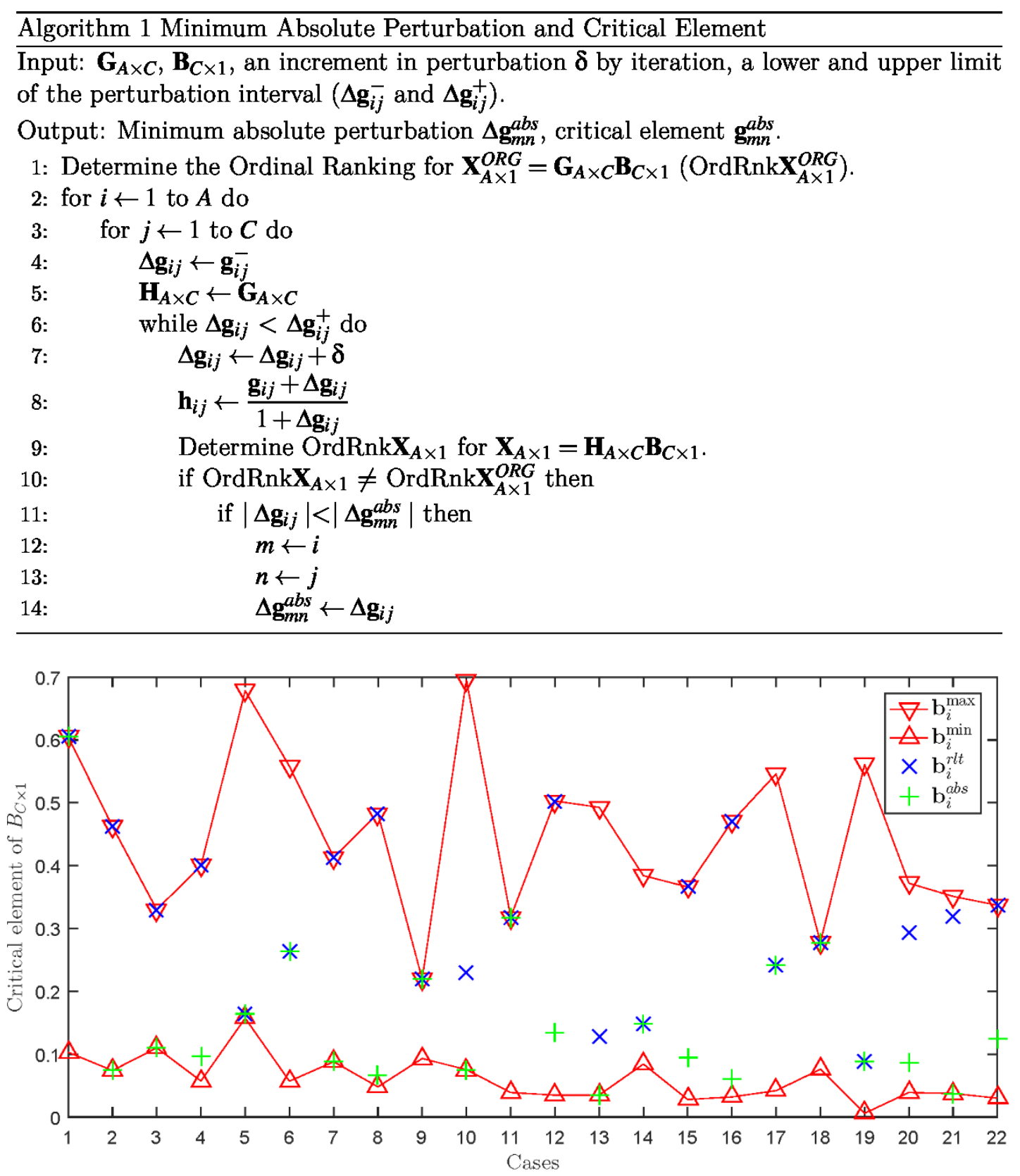

Figure 1. Positional analysis of the critical element of $\mathbf{B}_{C \times 1}$. 


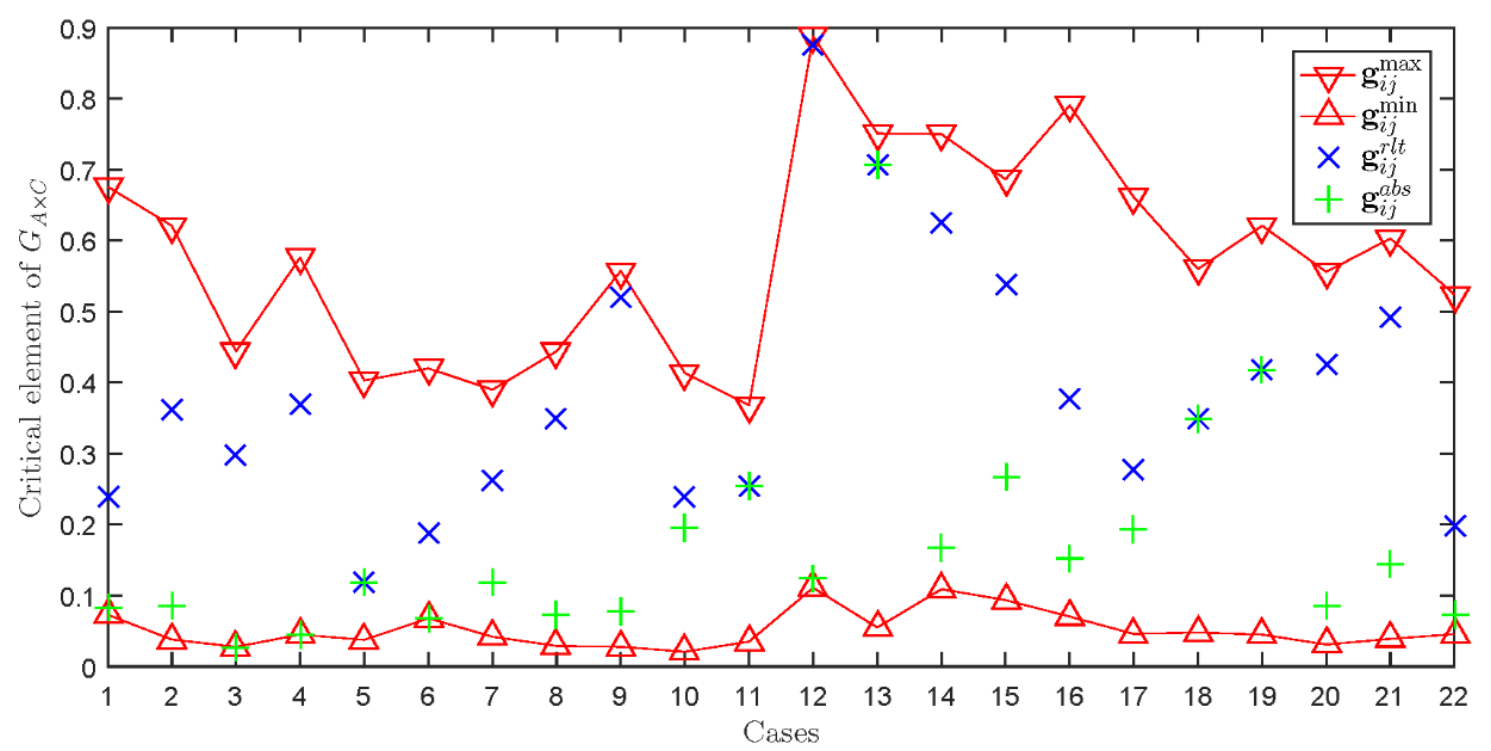

Figure 2. Positional analysis of the critical element of $\mathbf{G}_{A x C}$.

In Figure 1, for the critical element in $\mathbf{B}_{C \times 1}$ it can be noted that, among the 22 applications, in 13 applications $\mathbf{b}_{j}^{r l t}=\mathbf{b}_{j}^{\max }$, and in 6 applications $\mathbf{b}_{j}^{a b s}=\mathbf{b}_{j}^{\text {min }}$. These results are in accordance with conclusions found in Triantaphyllou \& Sánchez (1997). Moreover, in 9 applications $\mathbf{b}_{j}^{r l t}=\mathbf{b}_{j}^{a b s}$, and in 13 applications $\mathbf{b}_{j}^{r l t} \neq \mathbf{b}_{j}^{a b s}$. In Figure 2, for the critical element in $\mathbf{G}_{A x C}$ there are no applications with $\mathbf{g}_{i j}^{r l t}=\mathbf{g}_{i j}^{\max }$, in 3 applications $\mathbf{g}_{i j}^{a b s}=\mathbf{g}_{i j}^{\min }$, in 5 applications $\mathbf{g}_{i j}^{r l t}=\mathbf{g}_{i j}^{a b s}$, and in 17 applications $\mathbf{g}_{i j}^{r l t} \neq \mathbf{g}_{i j}^{a b s}$.

Figure 3 shows the relative values of the minimum perturbations for each application. Figure 4 shows the absolute values of the minimum perturbations for each application. The dashed line $y=0$ indicates minimum perturbation equal to zero. Therefore, the closer to this line the minimum perturbation is, the more sensitive to the rank reversal is the application. In general, considering the relative and absolute perturbations, the applications (Oliveira 2013; Su et al. 2014; Benítez et al. 2019) are less sensitive to the rank reversal. In the applications (Trevizano \& Freitas 2005; Giri \& Nejadhashemi 2014; Mendes et al. 2014; Alves \& Alves 2015) it is possible to notice the following intriguing behavior. If in relative terms $\Delta \mathbf{b}_{j}^{r l t}=\Delta \mathbf{g}_{i j}^{r l t}$ or very close, then in absolute terms $\Delta \mathbf{b}_{j}^{a b s}=\Delta \mathbf{g}_{i j}^{a b s}$ and the perturbations change signals. That is, if $\Delta \mathbf{b}_{j}^{r l t}$ $\simeq \Delta \mathbf{g}_{i j}^{r l t} \lessgtr 0$, then $\Delta \mathbf{b}_{j}^{a b s} \simeq \Delta \mathbf{g}_{i j}^{a b s} \gtrless 0$. The opposite sentence is not true.

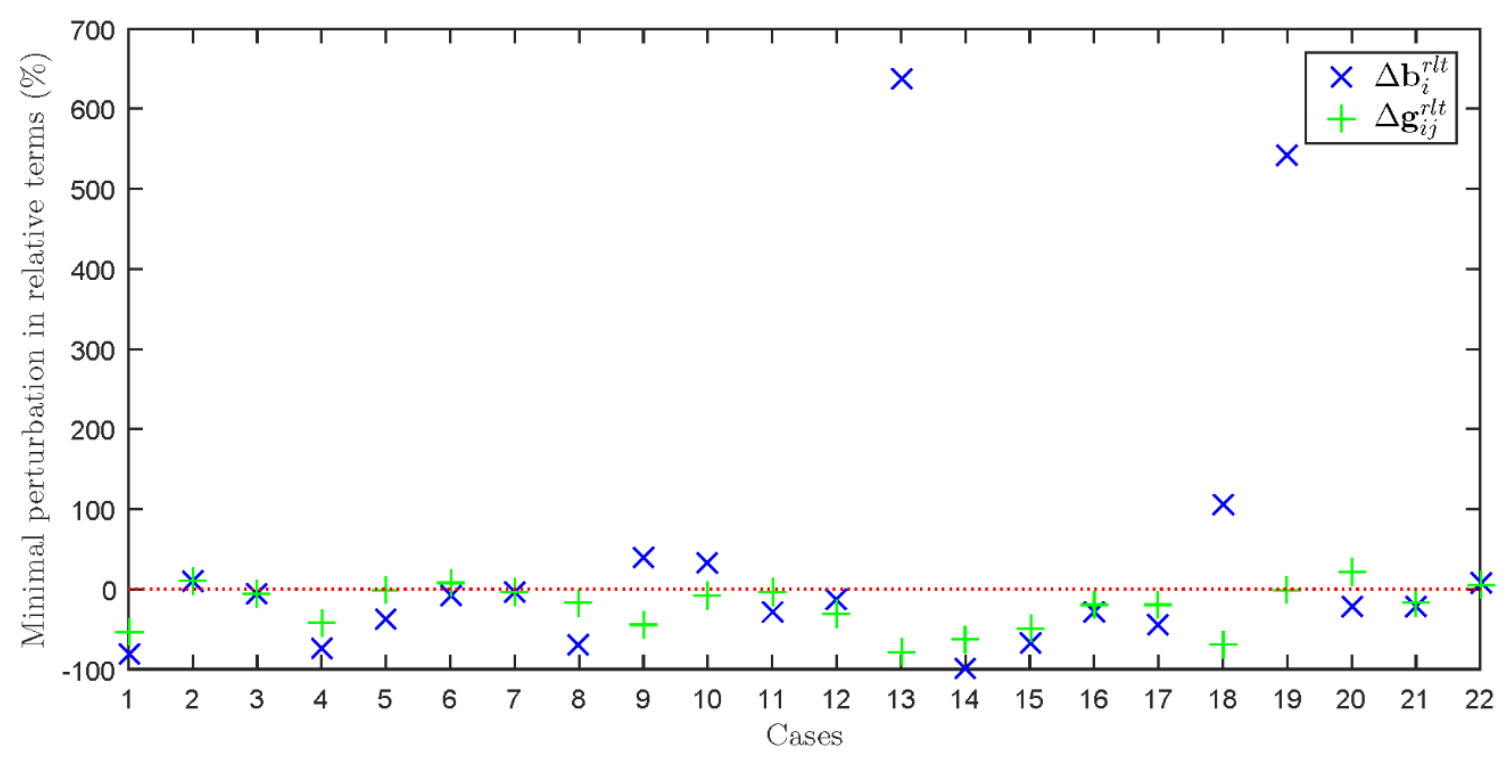

Figure 3. Relative minimal perturbations in the critical elements of $\mathbf{B}_{C \times 1}$ and $\mathbf{G}_{A \mathrm{x} C}$. 


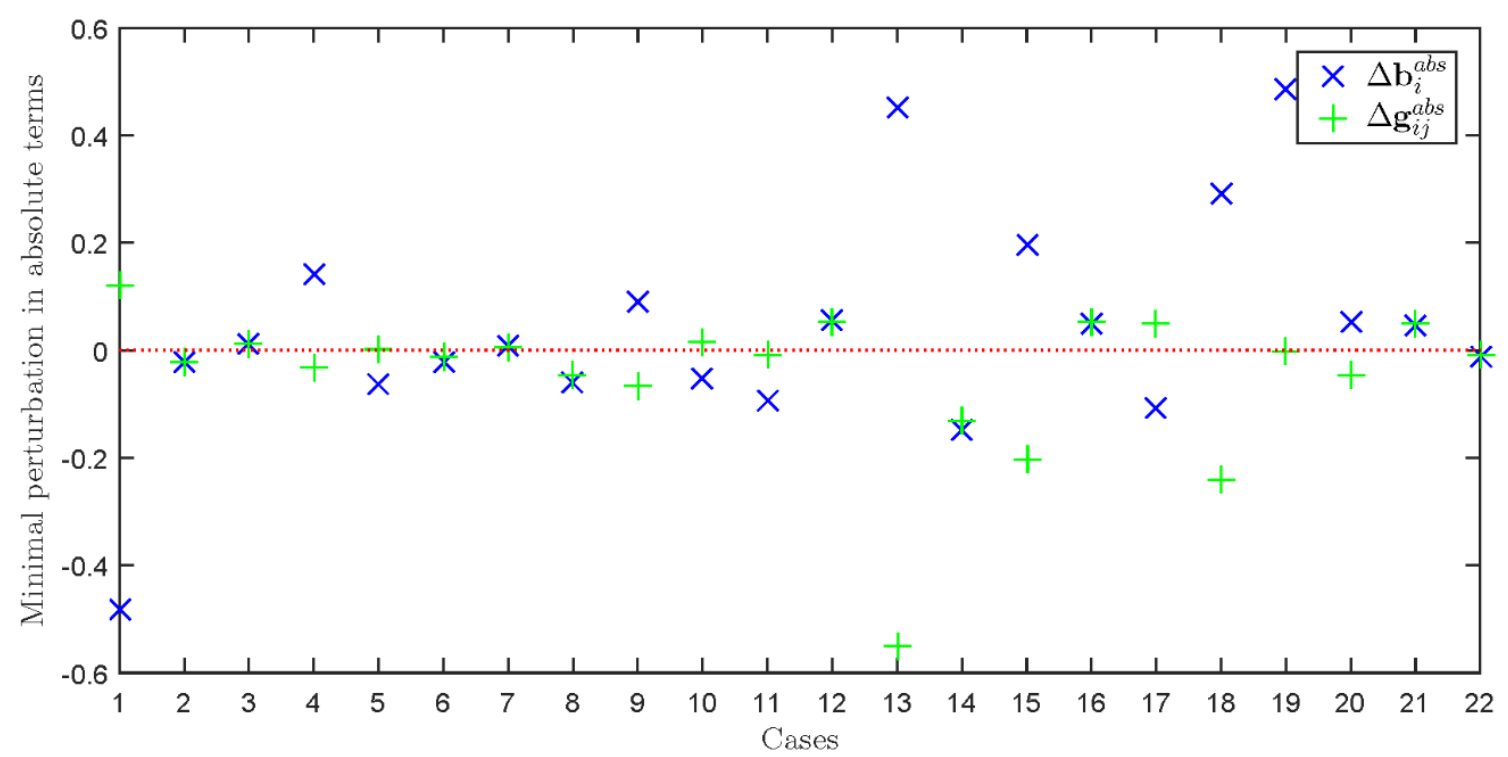

Figure 4. Absolute minimal perturbations in the critical elements of $\mathbf{B}_{C \times 1}$ and $\mathbf{G}_{A \times C}$.

To numerically exemplify the great sensitivity in some AHP applications, consider the case of de Paula \& Mello (2013), which corresponds to the point (case 5, -0.3320) of the relative minimum perturbations in Figure 3. In this case, a reduction of approximately $0.3320 \%$ in $\mathbf{g}_{41}$ is sufficient to invert the priorities in the alternatives. Note that alternatives 3 and 4 of the original solution $\mathbf{X}_{A \times 1}^{O R G}=\left[\begin{array}{llllll}\mathbf{A}_{6} & \mathbf{A}_{5} & \mathbf{A}_{4} & \mathbf{A}_{3} & \mathbf{A}_{2} & \mathbf{A}_{1}\end{array}\right]^{T}$ are switched to the perturbed solution $\mathbf{X}_{A \times 1}^{P T B}=$ $\left[\begin{array}{llllll}\mathbf{A}_{6} & \mathbf{A}_{5} & \mathbf{A}_{3} & \mathbf{A}_{4} & \mathbf{A}_{2} & \mathbf{A}_{1}\end{array}\right]^{T}$. This hypersensitivity shows that small variations in the main eigenvector of the local judgment matrix cause rank reversal when the variations occur in the critical element.

Finally, it is possible to conclude that there is no rule or law that indicates the critical element depending on the type of perturbation used. However, the empirical conclusions present in Triantaphyllou \& Sánchez (1997) can be considered as a trend, although they are not always verified. In addition, the critical element obtained with the relative perturbation may be different from the critical element obtained with the absolute perturbation.

\section{New sensitivity analysis of the AHP}

In essence, most of the sensitivity analyzes of the AHP are similar to those performed in the subsection above. For this reason it was called the typical sensitivity analysis of the AHP. It consists in finding the critical element, in relative or absolute terms, and estimating the smallest perturbation that causes the rank reversal (Triantaphyllou \& Sánchez 1997). However, this type of analysis does not estimate the sensitivity of the method with respect to vectors of priorities of the alternative with respect to each criterion or eigenvectors. That is, although it is possible to identify the most sensitive element (critical alternative or criterion), it is not possible to identify the most sensitive or critical eigenvector, even if this originates from judgments considered consistent. In Alvarez et al. (2021) it was suggested that estimating the sensitivity of the formulation with respect to the critical eigenvector may be as important as estimating the sensitivity with respect to the critical element.

Considering the Definition 1 in Alvarez et al. (2021) the following notation will be used. The column vector of $\mathbf{G}_{A x C}$ obtained after minimum relative perturbation in the critical element $\mathbf{g}_{i j}^{r l t}$ and normalization is $\mathbf{Z}_{A \times 1}^{j, r l t}$, where $j$ indicates the column of $\mathbf{G}_{A x C}$. The column vector of $\mathbf{G}_{A x C}$ obtained after minimal absolute perturbation in the critical element $\mathbf{g}_{i k}^{a b s}$ and normalization is $\mathbf{Z}_{A \times 1}^{k, a b s}$. The critical column vector of $\mathbf{G}_{A \times C}$ is denoted by $\mathbf{Z}_{A \times 1}^{j, c r t}$. This vector can be understood to the column vector $\mathbf{Z}_{A \times 1}^{j}$ that causes any change in ranking of $\mathbf{X}_{A \times 1}^{O R G}$ with the smallest possible $\left\|\Delta \mathbf{Z}_{A \times 1}^{j}\right\| 2 /\left\|\mathbf{Z}_{A \times 1}^{j}\right\| 2$, and it is determined by equation (5) 


$$
\frac{\left\|\Delta \mathbf{Z}_{A \times 1}^{j, c r t}\right\|_{2}}{\left\|\mathbf{Z}_{A \times 1}^{j, c r t}\right\|_{2}}=\min _{\substack{\forall l \in[1, C] \\ \forall \mathbf{Z}_{A \times 1}^{l, p t b}}}\left\{\frac{\left\|\Delta \mathbf{Z}_{A \times 1}^{l}\right\|_{2}}{\left\|\mathbf{Z}_{A \times 1}^{l}\right\|_{2}}\right\}=\min _{\substack{\forall l \in[1, C] \\ \forall \mathbf{Z}_{A \times 1}^{l, p t b}}}\left\{\frac{\left\|\mathbf{Z}_{A \times 1}^{l, p t b}-\mathbf{Z}_{A \times 1}^{l}\right\|_{2}}{\left\|\mathbf{Z}_{A \times 1}^{l}\right\|_{2}}\right\}
$$

where $\mathbf{Z}_{A \times 1}^{l, p t b}$ denotes the perturbed column vector. It must be said that in all cases of application of the AHP the critical column vector found with relative perturbation coincides with the one found with absolute perturbation. Deterministic, heuristic or stochastic methods can be used to determine the column vector, which when perturbed entirely minimizes the error $\left\|\Delta \mathbf{Z}_{A \times 1}^{l}\right\| 2 /\left\|\mathbf{Z}_{A \times 1}^{l}\right\| 2$ for all $l$. Here, a stochastic method was used, where $\Delta \mathbf{Z}_{A \times 1}^{l, r d m}$ denotes the random column vector, which is obtained by randomly perturbing all the components of $\mathbf{Z}_{A \times 1}^{l}$.

The Algorithm 2 shows the idea of this stochastic method. The idea is to randomly generate a sample of $Q$ vectors that are uniformly distributed in a region close to the unperturbed vector $\mathbf{Z}_{A \times 1}^{l}$. All of these vectors $\mathbf{Z}_{A \times 1}^{l, p t b}$ have the same dimension and are normalized. The generation of these random vectors is stopped when $10 \times Q$ vectors that cause rank reversals with an error greater than Error $_{\min }$ are counted. This is the stopping criterion for the loop.

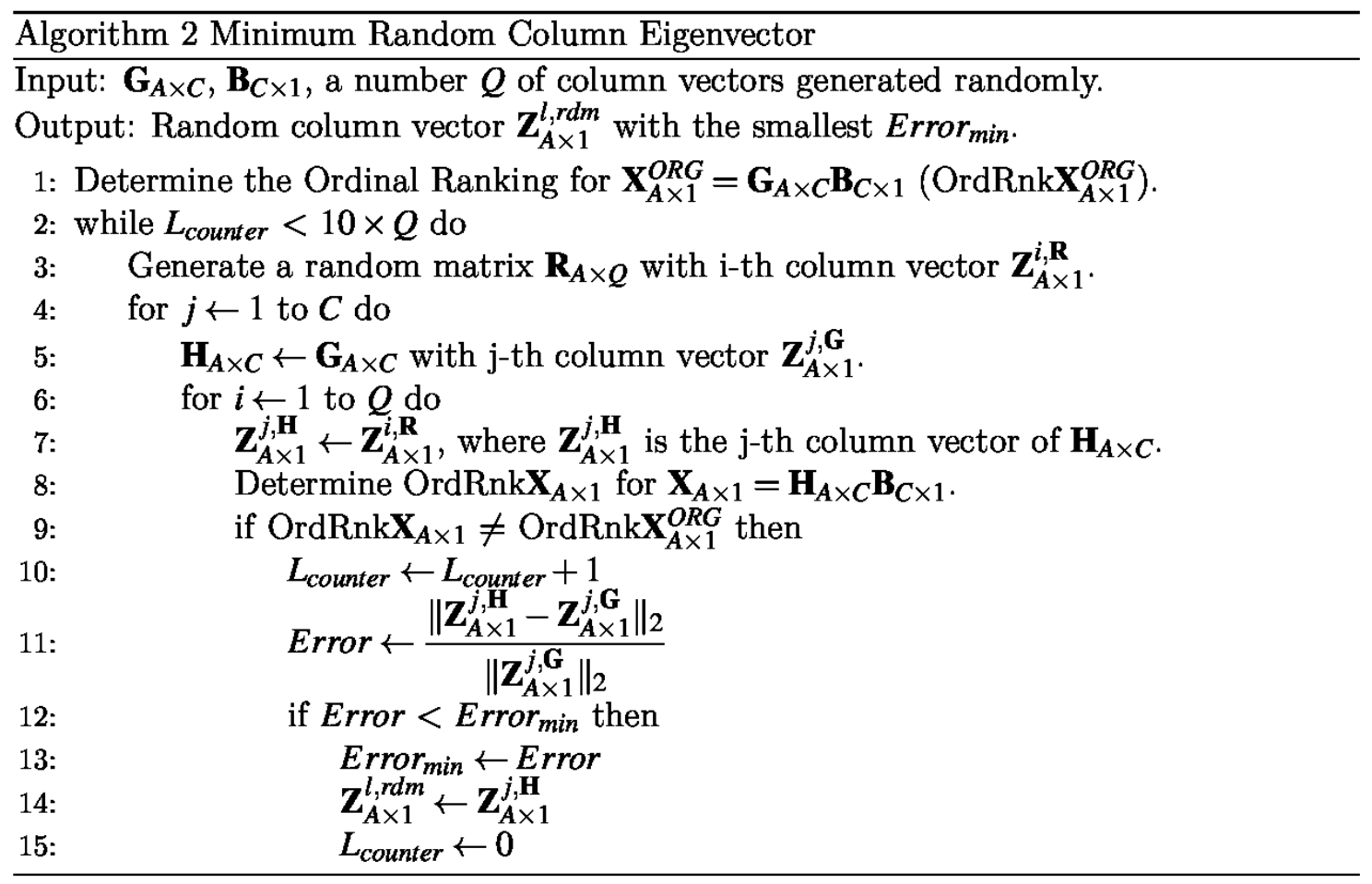

The critical column vector will be the one with the smallest relative error between $\mathbf{Z}_{A \times 1}^{j, r l t}$, $\mathbf{Z}_{A \times 1}^{k, a b s}$ and $\mathbf{Z}_{A \times 1}^{\text {,rdm }}$. For example, consider the case present in Cabała (2010), which originally has the column vector $\mathbf{Z}_{3 \times 1}^{6}$. When a minimum relative perturbation of $-19.7355 \%$ is made in $\mathbf{g}_{16}^{r l t}$, the perturbed vector after normalization becomes $\mathbf{Z}_{3 \times 1}^{6, r l t}$, and the less priority alternative that was previously $\mathbf{A}_{2}$ becomes $\mathbf{A}_{1}$. When an absolute minimum perturbation of 0.0535 is made in $\mathbf{g}_{26}^{a b s}$, the perturbed vector after normalization becomes $\mathbf{Z}_{3 \times 1}^{6, a b s}$, and a similar inversion of the alternatives occurs. This same rank reversal also occurs when $\mathbf{Z}_{3 \times 1}^{6}$ becomes $\mathbf{Z}_{3 \times 1}^{6, r d m}$, where $\mathbf{Z}_{3 \times 1}^{6, r d m}$ is obtained from $\mathbf{Z}_{3 \times 1}^{6}$ with the Algorithm 2 by randomly perturbing all its components. However, as $\mathbf{Z}_{3 \times 1}^{6, r d m}$ has the smallest $\left\|\Delta \mathbf{Z}_{3 \times 1}^{6}\right\| 2 /\left\|\mathbf{Z}_{3 \times 1}^{6}\right\| 2$ among the three mentioned perturbations, then this vector will be considered the critical column vector of $\mathbf{G}_{A x C}$. The details of this example are described in Table 2. 
Table 2. Perturbations in the column vectors of the case (Cabała 2010).

\begin{tabular}{|c|c|c|c|c|}
\hline Alternative & $\mathbf{Z}_{3 \times 1}^{6}$ & $\mathbf{Z}_{3 \times 1}^{6, r l t}$ & $\mathbf{Z}_{3 \times 1}^{6, a b s}$ & $\mathbf{Z}_{3 \times 1}^{6, \text { rdm }}$ \\
\hline $\mathbf{A}_{1}$ & 0.3767 & 0.3266 & 0.3576 & 0.3456 \\
\hline $\mathbf{A}_{2}$ & 0.1513 & 0.1634 & 0.1944 & 0.1825 \\
\hline $\mathbf{A}_{3}$ & 0.4720 & 0.5099 & 0.4480 & 0.4729 \\
\hline$\frac{\left\|\Delta \mathbf{Z}_{3 \times 1}^{6}\right\|_{2}}{\left\|\mathbf{Z}_{3 \times 1}^{6}\right\|_{2}}$ & $0 \%$ & $10.2735 \%$ & $8.4943 \%$ & $\mathbf{7 . 0 6 8 9} \%$ \\
\hline
\end{tabular}

Figure 5 shows the data in Table 3, where all 22 analyzed applications are compared. In several cases it is possible to notice that the relative errors of the randomly generated vectors are below the relative errors generated by minimal relative or absolute perturbations. That is, in several cases the AHP is more sensitive to perturbations in the eigenvector as a whole than to perturbations in the critical element of $\mathbf{G}_{A x C}$. In addition, observing the Table 3, it is possible to notice two peculiarities about the $j$ position of the critical column vector $\mathbf{Z}_{A \times 1}^{j, c r t}$. First, it can be noted that the column that generates the lowest $\frac{\left\|\Delta \mathbf{Z}_{A 1}^{j, r l}\right\|_{2}}{\left\|\mathrm{Z}_{A \times 1}^{j}\right\|_{2}}$ may differ from the column with the lowest $\frac{\left\|\Delta \mathbf{Z}_{A \times 1}^{k, a b s}\right\|_{2}}{\left\|\mathbf{Z}_{A \times 1}^{k}\right\|_{2}}$, that is, $j \neq k$ (Al-Harbi 2001; Lucena \& Mori 2018; Benítez et al. 2019). This result was expected by the sensitivity analysis carried out in the previous section. Second, the $j$ position associated with $\mathbf{Z}_{A \times 1}^{j, c r t}$ tends to match the column that generates the smallest $\frac{\left\|\Delta \mathbf{Z}_{A 1}^{k, a b s}\right\| 2}{\left\|\mathbf{Z}_{A \times 1}^{k}\right\| 2}$. However, in the cases (de Paula \& Mello 2013; Giri \& Nejadhashemi 2014; Damdinsuren \& Ishdamba 2017) the column where the critical element is located does not match the column $j$ of $\mathbf{Z}_{A \times 1}^{j, c r t}$. This indicates that the critical element does not necessarily belong to the critical column vector. In most cases $\frac{\left\|\Delta \mathbf{Z}_{A \times 1}^{k, a b s}\right\| 2}{\left\|\mathbf{Z}_{A \times 1}^{k}\right\| 2} \leq \frac{\left\|\Delta \mathbf{Z}_{A \times 1}^{j}, r l t\right\|_{2}}{\left\|\mathbf{Z}_{A \times 1}^{j}\right\| 2}$, however in the case (Oliveira 2013) $\frac{\left\|\Delta \mathbf{Z}_{A \times 1}^{j}, r l t\right\|_{2}}{\left\|\mathbf{Z}_{A \times 1}^{j}\right\| 2} \leq \frac{\left\|\Delta \mathbf{Z}_{A 1}^{k, a b s}\right\| 2}{\left\|\mathbf{Z}_{A \times 1}^{k}\right\| 2}$. In addition, in some cases $\frac{\left\|\Delta \mathbf{Z}_{A \times 1}^{l, r d m}\right\| 2}{\left\|\mathbf{Z}_{A \times 1}^{l}\right\| 2} \leq \frac{\left\|\Delta \mathbf{Z}_{A 1}^{k, a b s}\right\| 2}{\left\|\mathbf{Z}_{A \times 1}^{k}\right\| 2}$, and in other cases $\frac{\left\|\Delta \mathbf{Z}_{A 1}^{k, a b s}\right\| 2}{\left\|\mathbf{Z}_{A \times 1}^{k}\right\| 2} \leq \frac{\left\|\Delta \mathbf{Z}_{A \times 1}^{l, r d m}\right\| 2}{\left\|\mathbf{Z}_{A \times 1}^{l}\right\| \|_{2}}$. This indicates that to find the critical column vector it is not sufficient to make the perturbation only in the critical element, but also in all the components of the column vector.

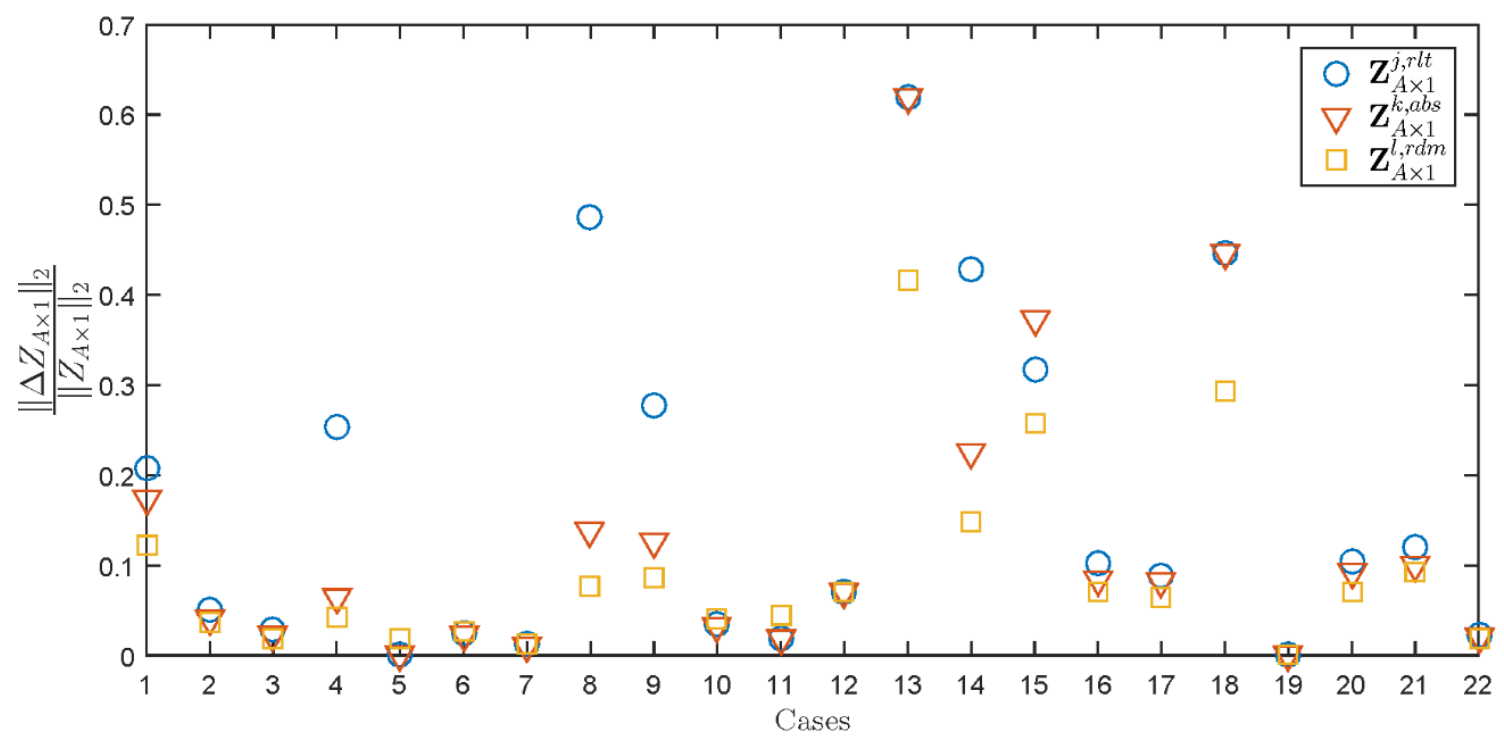

Figure 5. Minimum perturbations in column vectors of $\mathbf{G}_{A x C}$ : relative and absolute perturbations in the critical element $\left(\mathbf{Z}_{A \times 1}^{j, r l t}\right.$ and $\left.\mathbf{Z}_{A \times 1}^{j, a b s}\right)$, and perturbations in the random column vector $\left(\mathbf{Z}_{A \times 1}^{j, r d m}\right)$. 
Table 3. Perturbations in $\mathbf{G}_{A x C}$ to find the critical column vector.

\begin{tabular}{|c|c|c|c|c|c|c|c|}
\hline Case & Reference & $j, r l$ & $\frac{\left\|\Delta \mathbf{Z}_{A \times 1}^{j, r l t}\right\|_{2}}{\left\|\mathbf{Z}_{A \times 1}^{j}\right\|_{2}}$ & $k, a b s$ & $\frac{\left\|\Delta \mathbf{Z}_{A \times 1}^{k, a b s}\right\|_{2}}{\left\|\mathbf{Z}_{A \times 1}^{k}\right\|_{2}}$ & $l, r d m$ & $\frac{\left\|\Delta \mathbf{Z}_{A \times 1}^{l, r d m}\right\|_{2}}{\left\|\mathbf{Z}_{A \times 1}^{l}\right\|_{2}}$ \\
\hline 1 & Su et al. (2014) & 1 & 0.2081 & 1 & 0.1732 & 1 & 0.1217 \\
\hline 2 & Trevizano \& Freitas (2005) & 1 & 0.0513 & 1 & 0.0408 & 1 & 0.0370 \\
\hline 3 & Giri \& Nejadhashemi (2014) & $\underline{5}$ & 0.0292 & $\underline{5}$ & 0.0225 & $\underline{1}$ & 0.0191 \\
\hline 4 & dos Anjos Bainha et al. (2018) & 3 & 0.2530 & 3 & 0.0645 & 3 & 0.0425 \\
\hline 5 & de Paula \& Mello (2013) & $\underline{1}$ & 0.0008 & $\underline{1}$ & 0.0008 & $\underline{3}$ & 0.0185 \\
\hline 6 & Sbeity et al. (2014) & 3 & 0.0256 & 3 & 0.0226 & 3 & 0.0271 \\
\hline 7 & Alves \& Alves (2015) & 2 & 0.0122 & 2 & 0.0110 & 2 & 0.0122 \\
\hline 8 & Koksal \& Ozmutaf (2009) & 2 & 0.4855 & 2 & 0.1390 & 2 & 0.0756 \\
\hline 9 & Lucena \& Mori (2018) & $\underline{1}$ & 0.2777 & $\underline{3}$ & 0.1270 & $\underline{3}$ & 0.0858 \\
\hline 10 & Schmidt (1995) & 1 & 0.0347 & 1 & 0.0338 & 1 & 0.0406 \\
\hline 11 & Wollmann et al. (2012) & 5 & 0.0189 & 5 & 0.0189 & 5 & 0.0456 \\
\hline 12 & Franco et al. (2017) & 1 & 0.0708 & 1 & \begin{tabular}{|l|}
0.0708 \\
\end{tabular} & 1 & 0.0708 \\
\hline 13 & de Abreu et al. (2000) & 1 & 0.6187 & 1 & 0.6187 & 1 & 0.4168 \\
\hline 14 & Benítez et al. (2019) & $\underline{4}$ & 0.4279 & $\underline{1}$ & 0.2266 & $\underline{1}$ & 0.1488 \\
\hline 15 & Oliveira (2013) & 1 & 0.3163 & 1 & 0.3728 & 1 & 0.2584 \\
\hline 16 & Cabała (2010) & 6 & 0.1027 & 6 & 0.0849 & 6 & 0.0707 \\
\hline 17 & Chalúpková \& Franek (2014) & 1 & 0.0886 & 1 & 0.0825 & 1 & 0.0654 \\
\hline 18 & Shahroodi et al. (2012) & 1 & 0.4466 & 1 & 0.4466 & 1 & 0.2938 \\
\hline 19 & Gomede \& Barros (2012) & 4 & 0.0012 & 4 & 0.0012 & 4 & 0.0013 \\
\hline 20 & Al-Harbi (2001) & $\underline{2}$ & 0.1050 & $\underline{1}$ & 0.0931 & $\underline{1}$ & 0.0699 \\
\hline 21 & Damdinsuren \& Ishdamba (2017) & $\underline{2}$ & 0.1199 & $\underline{2}$ & 0.1009 & $\underline{1}$ & 0.0915 \\
\hline 22 & Mendes et al. (2014) & $\overline{9}$ & 0.0226 & 9 & 0.0201 & $\overline{9}$ & 0.0194 \\
\hline
\end{tabular}

\section{Sensitivity analysis via condition number}

As presented in Alvarez et al. (2021) the condition number allows estimating a measure of the sensitivity of a linear method. Thus, the higher the condition number of the matrix, the more sensitive this formulation will be to perturbations in its input data. This type of sensitivity analysis allows us to estimate how uncertainties and/or inaccuracies impact the solution of the linear formulation. Within the scope of AHP, this analysis can be applied to its two formulations: original and equivalent.

The theoretical developments carried out in Alvarez et al. (2021) will be shown here in graphical form. The central idea is to plot graphs, whose $x$ axis represents the relative error of the input data $\frac{\left\|\Delta \mathbf{G}_{A x C}\right\| m}{\left\|\mathbf{G}_{A x C}\right\| m}$ or $\frac{\left\|\Delta \mathbf{B}_{C \times 1}\right\| m}{\left\|\mathbf{B}_{C \times 1}\right\| m}$, and the $y$ axis represents the relative error in the solution $\frac{\left\|\Delta \mathbf{X}_{A \times 1}^{O R G}\right\| m}{\left\|\mathbf{X}_{A \times 1}^{O R G}\right\| m}$ or $\frac{\left\|\Delta \mathbf{X}_{A \times 1}^{E Q V}\right\| m}{\left\|\mathbf{X}_{A \times 1}^{E Q V}\right\| m}$. Two ways of generating these relative errors are considered: (I) variations on the critical element of $\mathbf{G}_{A \times C}\left(\mathbf{g}_{i j}^{a b s}\right)$ or $\mathbf{B}_{C \times 1}\left(\mathbf{b}_{j}^{a b s}\right)$ with absolute perturbations increased in $\delta=10^{-6}$, (II) variations on the entire critical column vector with random perturbations.

In all plotted graphs, there will be two vertical lines determined by the critical element of $\mathbf{G}_{A \times C}$ or $\mathbf{B}_{C \times 1}$, called Rank Reversals (1) and Bound of infeasible. The vertical line Rank Reversals (1) corresponds to the smallest $\frac{\left\|\Delta \mathbf{G}_{A \times C}\right\| 2}{\left\|\mathbf{G}_{A x C}\right\|^{2}}$ or $\frac{\left\|\Delta \mathbf{B}_{C \times 1}\right\|^{2}}{\left\|\mathbf{B}_{C \times 1}\right\|^{2}}$ value from which the rank reversal occurs when only the critical element is perturbed in the column vector. Meanwhile, the vertical line Bound of infeasible corresponds to the limit value of viable perturbations of the critical element. In the context of the AHP, a perturbation is considered viable if the vectors that are generated can be normalized with componentes in the range $] 0,1\left[\right.$ and not very small values $\left(\mathbf{g}_{i j}\right.$ or $\mathbf{b}_{j}>$ 
0.001). Thus, each graph is divided into three regions. First, the region before the vertical line Rank Reversals (1), where perturbations in critical element do not yet generate rank reversal. Second, the region between the vertical lines Rank Reversals (1) and Bound of infeasible, where rank reversal exists. Third, the region after the vertical line Bound of infeasible, where rank reversal occurs with perturbed vectors that are not viable for AHP. The third vertical line is called Rank Reversals (2), and it is determined by the critical column vector. This line corresponds to the smallest $\frac{\left\|\Delta \mathbf{G}_{A x C}\right\| 2}{\left\|\mathbf{G}_{A x C}\right\| 2}$ or $\frac{\left\|\Delta \mathbf{B}_{C \times 1}\right\| 2}{\left\|\mathbf{B}_{C \times 1}\right\| 2}$ value from which the rank reversal occurs when all components of the critical column vector are perturbed.

Following the development described in Alvarez et al. (2021), the theoretical limit of the relative error of the solution defined by the equations (6) and (7) is plotted in each case. Five matrix norms $\|\circ\|_{m}$ were used to determine the relative error, which are presented in Table 4 for an arbitrary matrix $\mathbf{C}_{C x A}$ (Strang 1988; Demmel 1997; Gentle 2007; Quarteroni \& Saleri 2007; Lee 2012; Golub \& Van Loan 2013). For reasons of space, it is not possible to present this analysis for the 22 applications of AHP. Thus, three applications were selected, where each one has $\mathbf{G}_{A \times C}$ full rank with dimension $C>A$ (de Abreu et al. 2000) or $C=A$ (Trevizano \& Freitas 2005) or $C<$ $A$ (Sbeity et al. 2014). Two figures are presented for each application. The first figure (Figures 6 , 8 and 10) corresponds to the sensitivity analysis according to the relative error of $\mathbf{B}_{C \times 1}$. In these cases the vertical line Rank Reversals (2) corresponds to the perturbed vector $\mathbf{B}_{C \times 1}$ as a whole. The second figure (Figures 7, 9 and 11) corresponds to the sensitivity analysis according to the relative error of $\mathbf{G}_{A x C}$. All figures show the relative error of the solution for the original and equivalent formulations, and in the equivalent formulation the two appropriate choices for $\mathbf{C}_{C \times A}$ are considered. The Algorithm 3 presents the computational idea to build the graphs.

$$
\begin{aligned}
& \| \text { Thr. error } \|_{m}=\operatorname{cond}_{m}\left(\mathbf{G}_{A \times C}\right) \frac{\left\|\Delta \mathbf{B}_{C \times 1}\right\|_{m}}{\left\|\mathbf{B}_{C \times 1}\right\|_{m}} . \\
& \| \text { Thr. error } \|_{m}=\operatorname{cond}_{m}\left(\mathbf{G}_{A \times C}\right) \frac{\left\|\Delta \mathbf{G}_{A \times C}\right\|_{m}}{\left\|\mathbf{G}_{A \times C}\right\|_{m}} .
\end{aligned}
$$

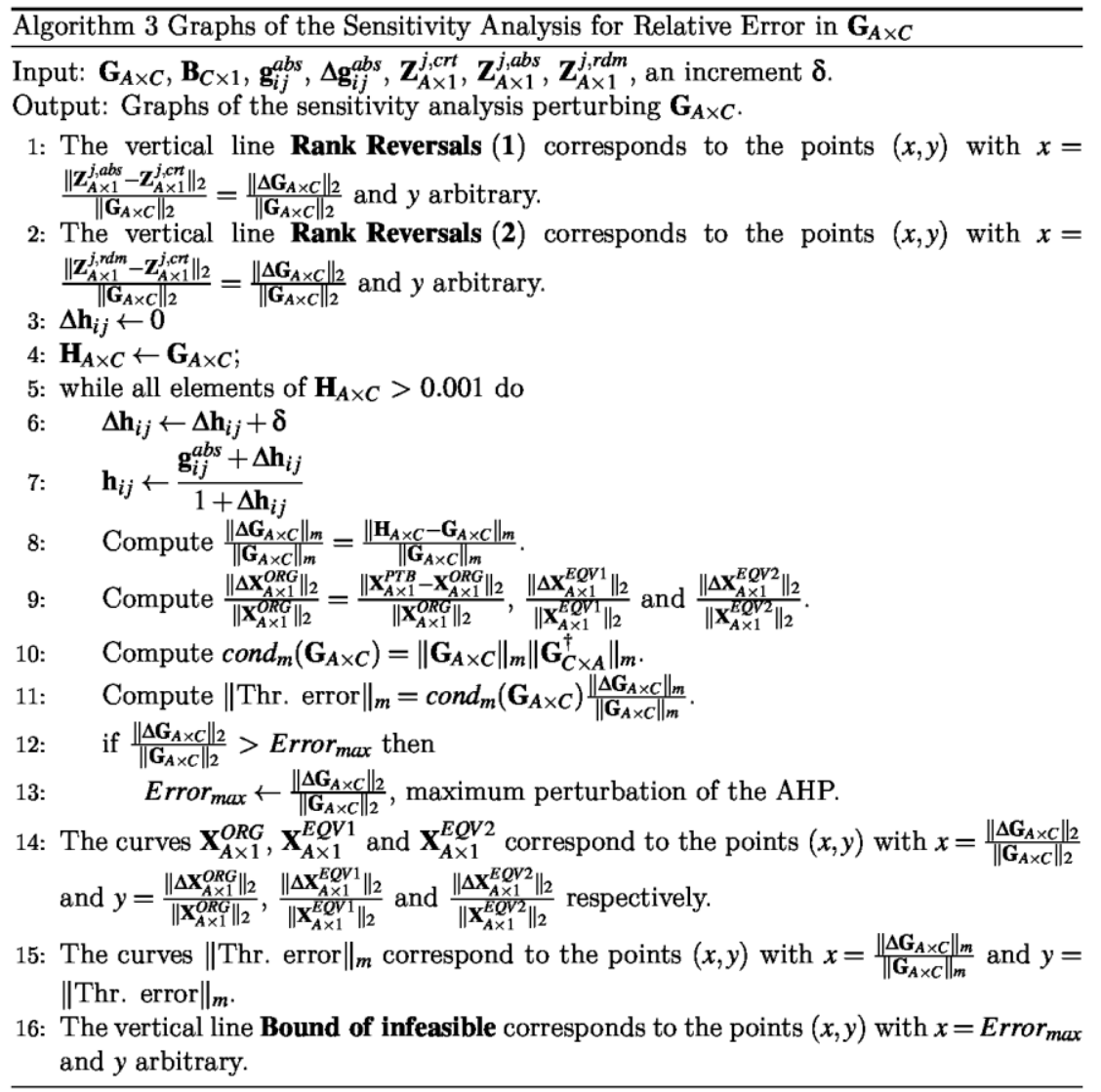


Table 4. Five matrix norms used in the sensitivity analysis.

\begin{tabular}{|c|c|}
\hline$m-$ Name & Norm Formulation \\
\hline $2-$ Euclidean & $\left\|\mathbf{C}_{C \times A}\right\|_{2}=\sum_{j=1}^{A} \sqrt{\sum_{i=1}^{C}\left|\mathbf{c}_{i j}\right|^{2}}$ \\
\hline 1 - Maximum absolute column sum & $\left\|\mathbf{C}_{C \times A}\right\|_{1}=\max _{1 \leq i \leq C}\left\{\sum_{j=1}^{A}\left|\mathbf{c}_{i j}\right|\right\}$ \\
\hline$\infty$ - Maximum absolute row sum & $\left\|\mathbf{C}_{C \times A}\right\|_{\infty}=\max _{1 \leq j \leq A}\left\{\sum_{i=1}^{C}\left|\mathbf{c}_{i j}\right|\right\}$ \\
\hline$F-$ Frobenius & $\left\|\mathbf{C}_{C \times A}\right\|_{F}=\sqrt{\sum_{i=1}^{C} \sum_{j=1}^{A}\left|\mathbf{c}_{i j}\right|^{2}}$ \\
\hline max -Maximum element & $\left\|\mathbf{C}_{C \times A}\right\|_{\max }=\max _{\substack{1 \leq i \leq C \\
1 \leq j \leq A}}\left\{\left|\mathbf{c}_{i j}\right|\right\}$ \\
\hline
\end{tabular}

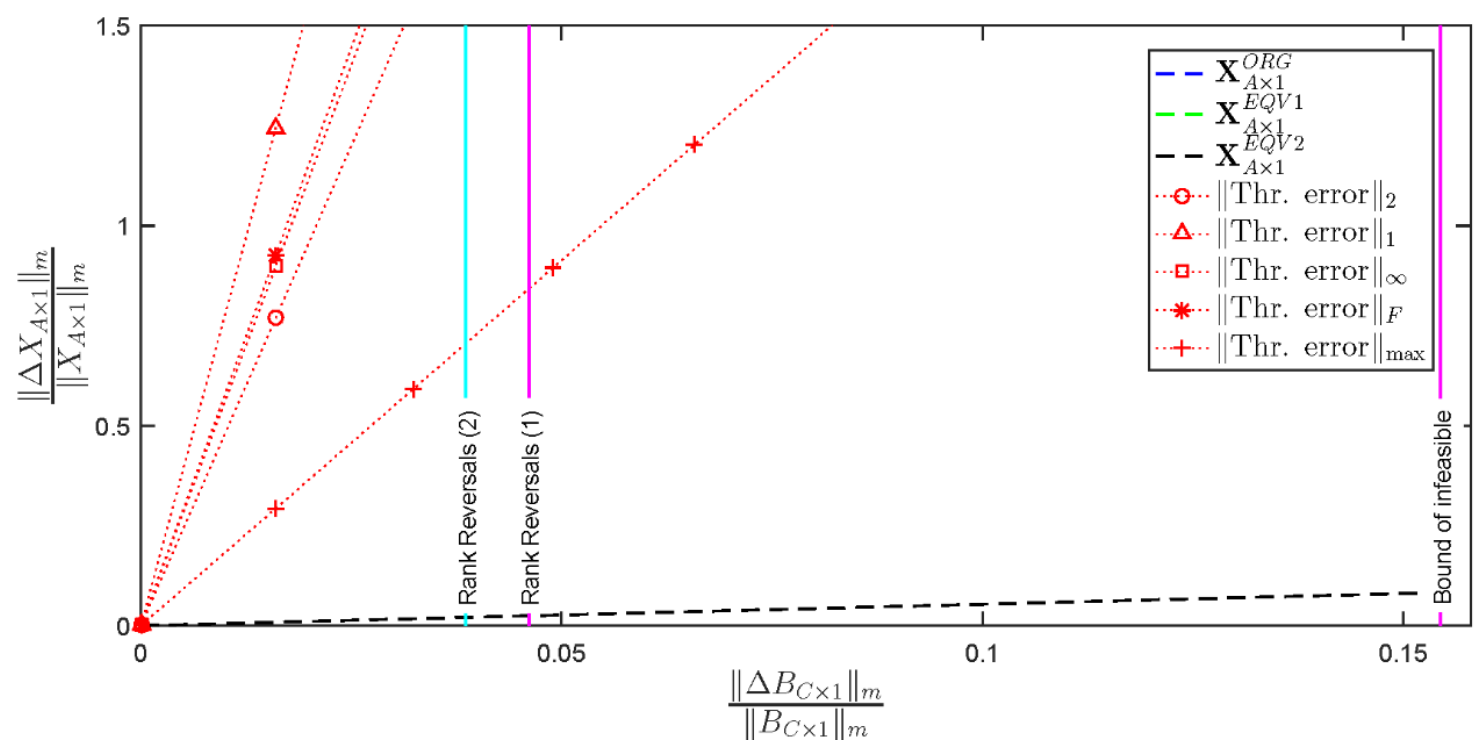

Figure 6. Sensitivity analysis perturbing $\mathbf{B}_{C \times 1}$ in case (Trevizano \& Freitas 2005) $(C=A)$.

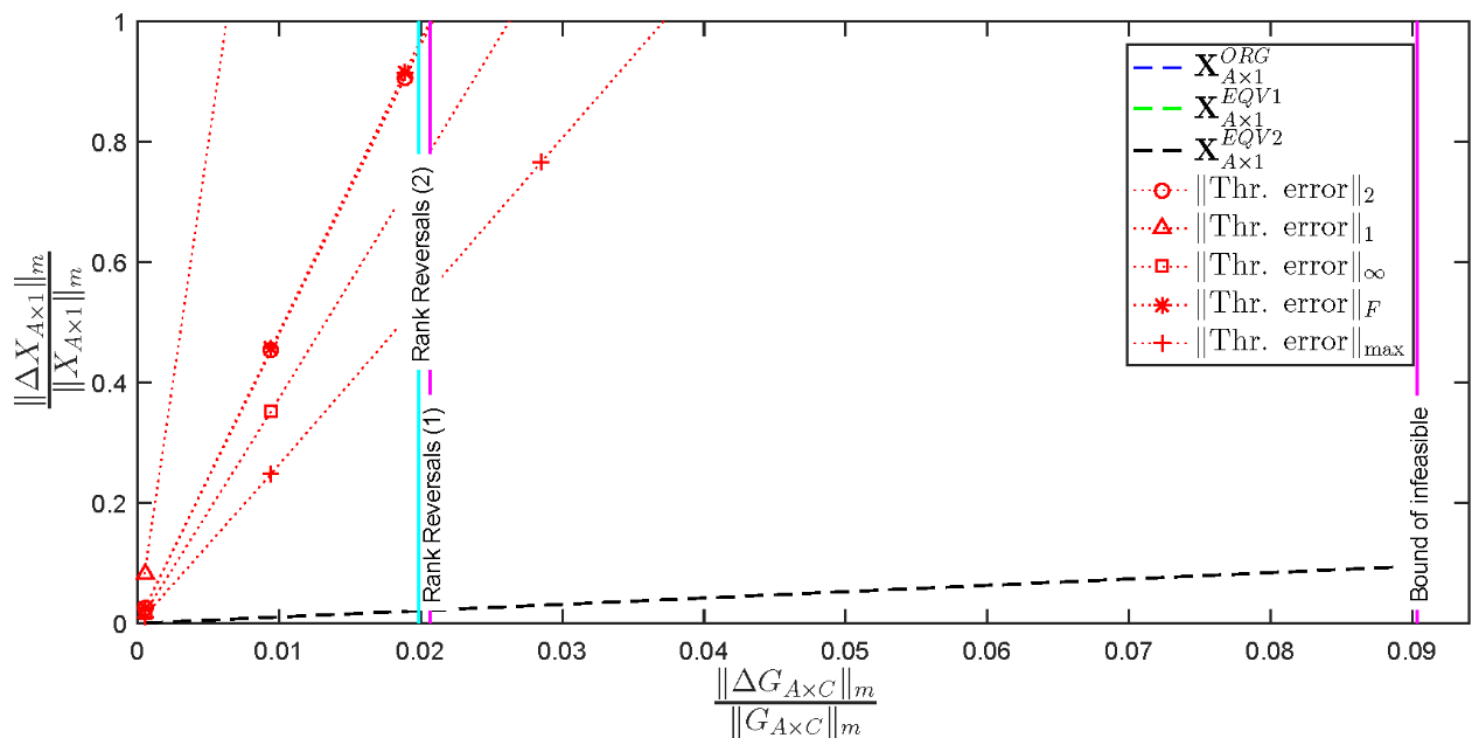

Figure 7. Sensitivity analysis perturbing $\mathbf{G}_{A x C}$ in case (Trevizano \& Freitas 2005) $(C=A)$. 


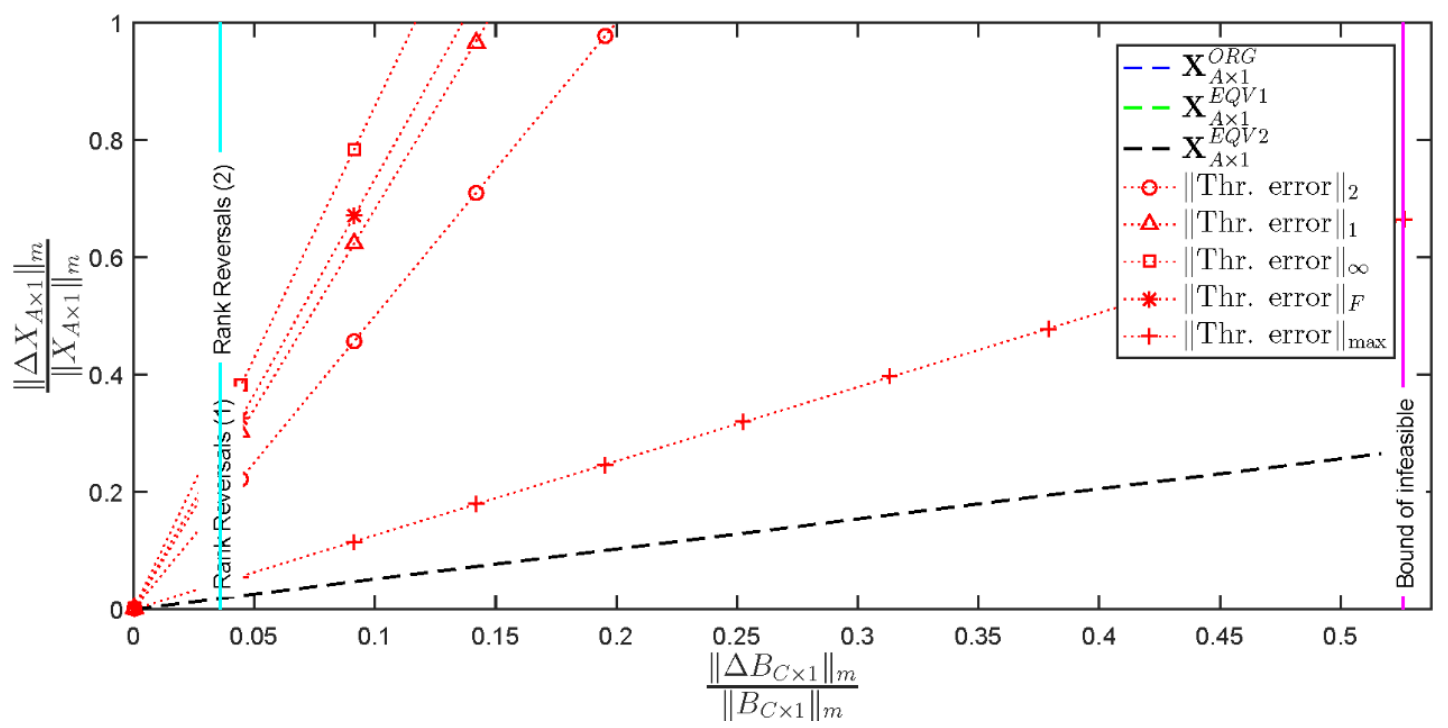

Figure 8. Sensitivity analysis perturbing $\mathbf{B}_{C \mathrm{x} 1}$ in case (Sbeity et al. 2014) $(C<A)$.

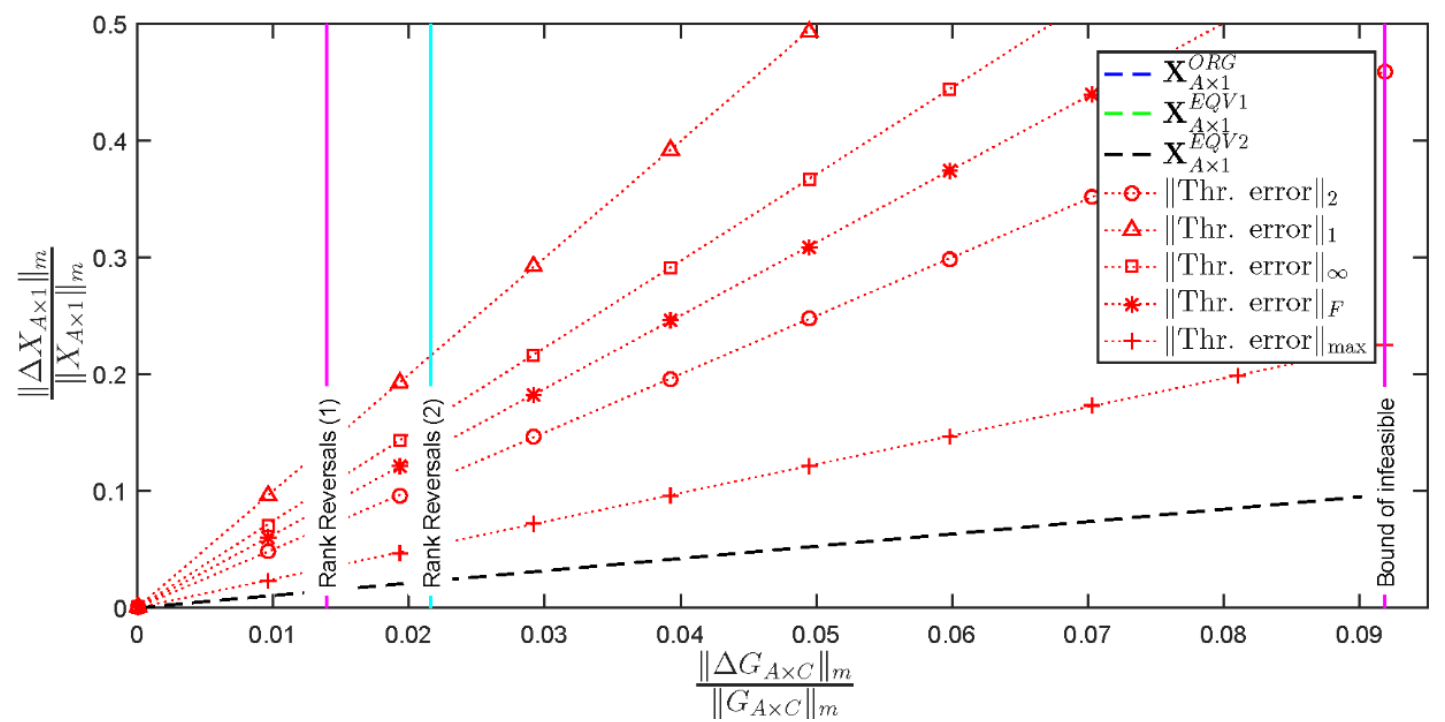

Figure 9. Sensitivity analysis perturbing $\mathbf{G}_{A \times C}$ in case (Sbeity et al. 2014) $(C<A)$.

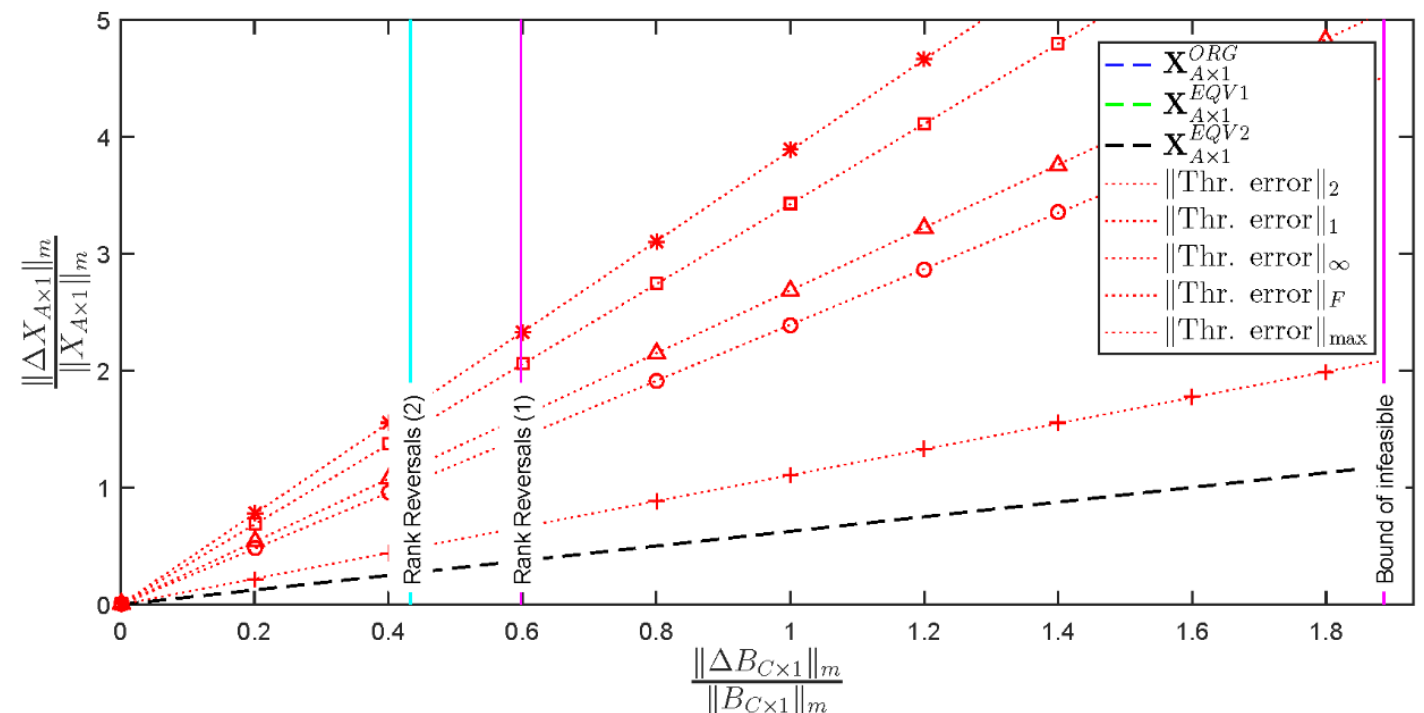

Figure 10. Sensitivity analysis perturbing $\mathbf{B}_{C \times 1}$ in case (de Abreu et al. 2000) $(C>A)$. 


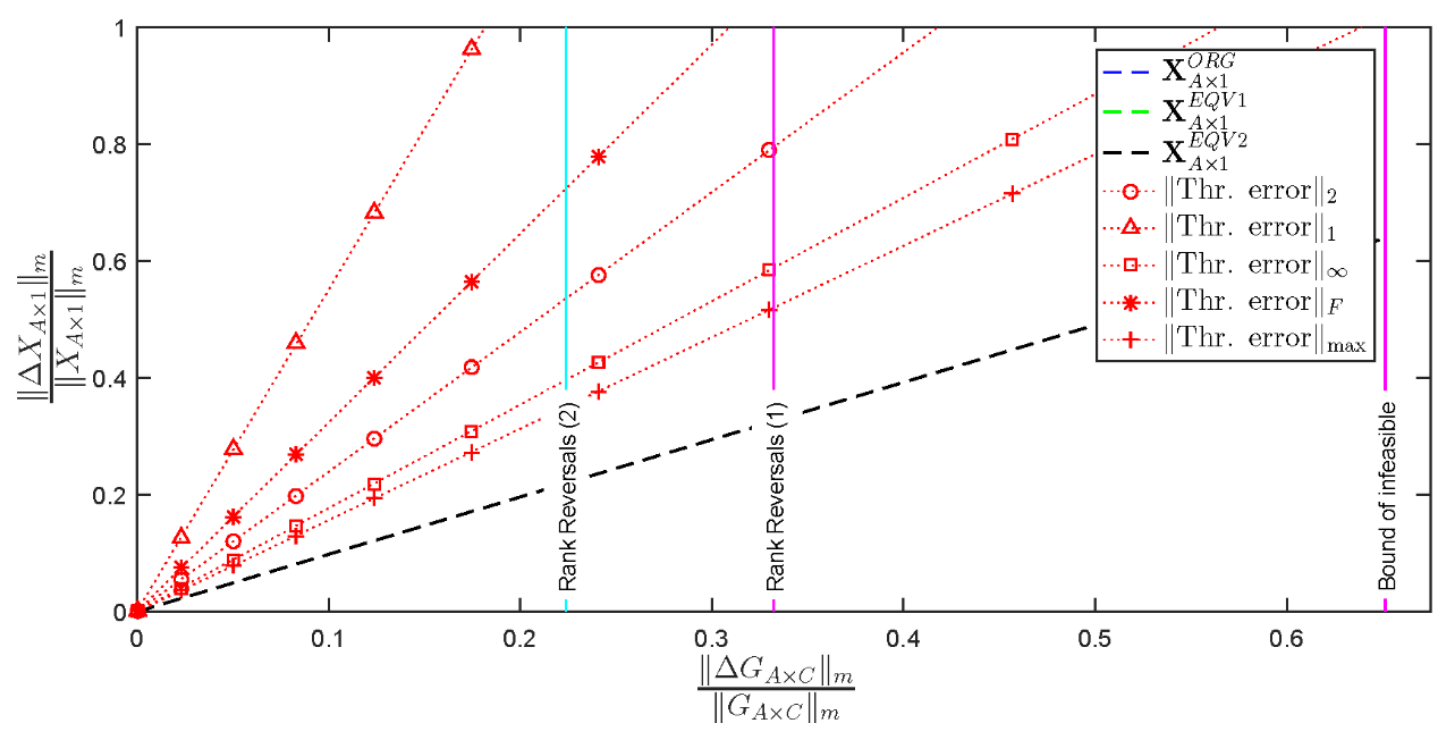

Figure 11. Sensitivity analysis perturbing $\mathbf{G}_{A x C}$ in case (de Abreu et al. 2000) $(C>A)$.

In all applications the curves $\mathbf{X}_{A \times 1}^{O R G}, \mathbf{X}_{A \times 1}^{E Q V 1}$ and $\mathbf{X}_{A \times 1}^{E Q V 2}$ are straight lines. In addition, in all figures it is not possible to notice a difference between the sensitivity of the original formulation and the equivalent for the two choices of $\mathbf{C}_{C \times A}$. That is, the curves $\mathbf{X}_{A \times 1}^{O R G}, \mathbf{X}_{A \times 1}^{E Q V 1}$ and $\mathbf{X}_{A \times 1}^{E Q V 2}$ always overlap. Therefore, the two formulations of AHP show similar sensitivity. This result justifies the new mathematical analysis of the AHP performed in Alvarez et al. (2021), and reinforces the equivalence between the formulations. If there was no overlap of the curves, the curve with the greatest relative error would represent the formulation with the greatest sensitivity, and consequently with the greatest chance of rank reversal.

In Figure 8 the vertical lines Rank Reversals (1) and Rank Reversals (2) show overlap. However, in Figures 6, 7, 9, 10 and 11 the vertical lines Rank Reversals (1) and Rank Reversals (2) do not match. This means that there is a difference between the sensitivity analysis considering only the critical element and the sensitivity analysis considering the critical column vector. Moreover, if the vertical line Rank Reversals (2) is positioned to the left of the vertical line Rank Reversals (1), then the formulation is more sensitive to the critical column vector than to the critical element. That is, the perturbation in the critical column vector that causes the rank reversal is less than the perturbation needed in the critical element for the rank reversal to arise. In other words, the typical or standard sensitivity analysis of the AHP is unable to reveal the rank reversal in a region where the sensitivity analysis via the critical column vector reveals. Furthermore, when considering the perturbation only in $\mathbf{B}_{C \times 1}$ for the three cases Rank Reversals (2) $\leq$ Rank Reversals (1). However, the same cannot be said for the perturbation only in $\mathbf{G}_{A x C}$, since in Figure 9 Rank Reversals (1) $\leq$ Rank Reversals (2). Therefore, this indicates that in order to have a more complete sensitivity analysis on the rank reversal effect it is necessary to carry out both analyzes: typical and the new one via the critical column vector.

In all cases, the curves $\mathbf{X}_{A \times 1}^{O R G}, \mathbf{X}_{A \times 1}^{E Q V 1}$ and $\mathbf{X}_{A \times 1}^{E Q V 2}$ were limited superiorly by the theoretical error in the five norms used. The theoretical errors closest to the curves $\mathbf{X}_{A \times 1}^{O R G}, \mathbf{X}_{A \times 1}^{E Q V 1}$ and $\mathbf{X}_{A \times 1}^{E Q V 2}$ were calculated using the norm $\|\circ\|_{\max }$. Theoretical errors calculated with the other four norms greatly overestimated the relative errors of the solutions $\mathbf{X}_{A \times 1}^{O R G}, \mathbf{X}_{A \times 1}^{E Q V 1}$ and $\mathbf{X}_{A \times 1}^{E Q V 2}$. The slope of each theoretical error curve is the condition number $\operatorname{cond}_{m}\left(\mathbf{G}_{A x C}\right)$, which is greater than the slope of the curves $\mathbf{X}_{A \times 1}^{O R G}, \mathbf{X}_{A \times 1}^{E Q V 1}$ and $\mathbf{X}_{A \times 1}^{E Q V 2}$. This shows the importance of choosing the appropriate norm to carry out a theoretical sensitivity analysis closer to the actual application cases. 


\section{Algebraic transformations when $G_{A x C}$ is deficient rank}

Among all the analyzed cases, only one application presented $\mathrm{G}_{A x C}$ with deficient rank (Koksal \& Ozmutaf 2009). In this case (Koksal \& Ozmutaf 2009) $C<A$ and $K=4$, where the column vectors $\mathbf{Z}_{5 \times 1}^{1}$ and $\mathbf{Z}_{5 \times 1}^{3}$ are parallel. Following the transformations described in Alvarez et al. (2021) it is possible to obtain a condensed formulation (8) with the same original solution. The condensed matrix $\widetilde{\mathbf{G}}_{6 \times 4}$ is full rank. The matrix $\widetilde{\mathbf{G}}_{6 \times 4}$ is condensed because its dimension is smaller than the dimension of $\mathbf{G}_{6 \times 5}$. Note that the LD column vectors of $\mathbf{G}_{6 \times 5}$ have not been removed from the analysis. These vectors were factored, and their weights were redistributed in $\tilde{\mathbf{b}}_{2}=\left(\mathbf{b}_{1}+\mathbf{b}_{3}\right)$. Note also that in this application case the two LD column vectors of $\mathbf{G}_{6 \times 5}$ are not ordered.

$$
\begin{aligned}
\mathbf{X}_{6 \times 1}^{O R G} & =\mathbf{G}_{6 \times 5} \mathbf{B}_{5 \times 1}=\left[\begin{array}{ccccc}
0.039 & 0.055 & 0.039 & 0.067 & 0.135 \\
0.063 & 0.074 & 0.063 & 0.370 & 0.444 \\
0.115 & 0.089 & 0.115 & 0.151 & 0.064 \\
0.245 & 0.171 & 0.245 & 0.190 & 0.048 \\
0.316 & 0.263 & 0.316 & 0.093 & 0.029 \\
0.221 & 0.348 & 0.221 & 0.129 & 0.280
\end{array}\right]\left[\begin{array}{c}
0.048 \\
0.483 \\
0.297 \\
0.106 \\
0.066
\end{array}\right] \\
& =\mathbf{b}_{1} \mathbf{Z}_{6 \times 1}^{1}+\mathbf{b}_{2} \mathbf{Z}_{6 \times 1}^{2}+\mathbf{b}_{3} \mathbf{Z}_{6 \times 1}^{3}+\mathbf{b}_{4} \mathbf{Z}_{6 \times 1}^{4}+\mathbf{b}_{5} \mathbf{Z}_{6 \times 1}^{5} \\
& =\mathbf{b}_{2} \mathbf{Z}_{6 \times 1}^{2}+\underbrace{\left(\mathbf{b}_{1}+\mathbf{b}_{3}\right)}_{\text {factoring }} \mathbf{Z}_{6 \times 1}^{3}+\mathbf{b}_{4} \mathbf{Z}_{6 \times 1}^{4}+\mathbf{b}_{5} \mathbf{Z}_{6 \times 1}^{5} \\
& =\left[\begin{array}{llll}
0.055 & 0.039 & 0.067 & 0.135 \\
0.074 & 0.063 & 0.370 & 0.444 \\
0.089 & 0.115 & 0.151 & 0.064 \\
0.171 & 0.245 & 0.190 & 0.048 \\
0.263 & 0.316 & 0.093 & 0.029 \\
0.348 & 0.221 & 0.129 & 0.280
\end{array}\right]\left[\begin{array}{l}
0.483 \\
0.345 \\
0.106 \\
0.066
\end{array}\right]=\tilde{\mathbf{G}}_{6 \times 4} \tilde{\mathbf{B}}_{4 \times 1}
\end{aligned}
$$

Two benefits of this algebraic transformations can be highlighted. First, choose appropriate for $\mathbf{C}_{C \times A}$, since the equations (3) and (4) are not the most appropriate. For example, a choice is given by the equation (9), which is similar to the equation (3) replacing $\mathbf{G}_{A x C}$ with $\widetilde{\mathbf{G}}_{A x K}$.

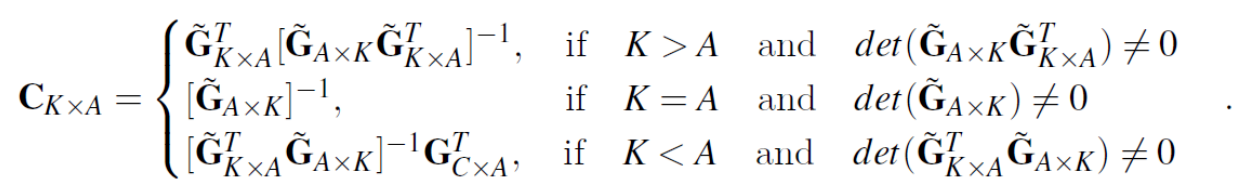

Another choice would be given by the equation (10)

$$
\mathbf{C}_{K \times A}=\tilde{\mathbf{G}}_{K \times A}^{T} .
$$

Since $\widetilde{\mathbf{G}}_{A \times K}$ is full rank it is not necessary to use special computational routines in MATLAB $^{\circledR}$ to solve $\mathbf{C}_{K \times A} \mathbf{X}_{A \times 1}^{E Q V}=\mathbf{C}_{K \times A} \mathbf{G}_{A \times C} \mathbf{B}_{C \times 1}=\mathbf{C}_{K \times A} \widetilde{\mathbf{G}}_{A \times K} \widetilde{\mathbf{B}}_{K \times 1}$.

The second benefit is the better condition number of the $\widetilde{\mathbf{G}}_{A \times K}$ when compared to $\mathbf{G}_{A x C}$. Table 5 shows the comparison between the formulations (1) and (8) for this case of deficient rank (Koksal \& Ozmutaf 2009). As can be seen, the condensed matrix has a much lower condition number. It is well known that a lower condition number ensures greater stability and 
robustness to the original and equivalent formulations. This is also verified in the highest value of the perturbation $\frac{\left\|\Delta \mathbf{Z}_{C \times 1}^{j, c r t}\right\| 2}{\left\|\mathbf{Z}_{C \times 1}^{j, c r t}\right\| 2}$ and $\frac{\left\|\Delta \mathbf{G}_{A x C}\right\| 2}{\left\|\mathbf{G}_{A x C}\right\| 2}$ needed to generate the rank reversals.

Tabela 5. Comparison between the original and condensed formulations in the case (Koksal \& Ozmutaf 2009).

\begin{tabular}{|c|c|c|c|c|c|}
\hline Model & Matrix & $K-$ rank & $\operatorname{cond}_{2}(\circ)$ & $\frac{\left\|\Delta \mathbf{Z}_{C \times 1}^{j, c t}\right\|_{2}}{\left\|\mathbf{Z}_{C \times 1}^{j, c t}\right\|_{2}}$ & $\frac{\left\|\Delta \mathbf{G}_{A \times C}\right\|_{2}}{\left\|\mathbf{G}_{A \times C}\right\|_{2}}$ \\
\hline Original & $\mathbf{G}_{6 \times 5}$ & 4-deficient & $1.96 \mathrm{E}+16$ & $7.73 \%$ & $4.26 \%$ \\
\hline Condensed & $\tilde{\mathbf{G}}_{6 \times 4}$ & 4-full & 26.36 & $10.12 \%$ & $4.96 \%$ \\
\hline
\end{tabular}

\section{The rank reversal effect on the AHP}

The rank reversals effect is common in AHP applications (Maleki \& Zahir 2013; Aires \& Ferreira 2018). This effect was detected in (Belton \& Gear 1983). Subsequently, several studies and debates have appeared trying to explain and avoid this effect. However, even today the debate remains open without definitive answers. In Part I of this research (Alvarez et al. 2021) a new mathematical analysis of the AHP is proposed. In this new analysis the AHP is formulated in terms of a linear system of algebraic equations. In this way, it is natural to perform the AHP sensitivity analysis via condition number. Consequently, the sensitivity analysis via condition number of any linear system leads to Remark 1 in (Alvarez et al. 2021). This remark states that the rank reversal is impossible to eliminate in AHP, and the results presented in the section above support this statement. As seen in all the figures in the section above, the rank reversal effect corresponds to a region delimited inferiorly by the vertical line Rank Reversals (1) or Rank Reversals (2) and superiorly by the vertical line Bound of infeasible. Since it is impossible for the lower and upper limits of this region to be the same, then in every application of AHP the rank reversal effect will always be present. To reduce or mitigate this effect, it is necessary that the vertical lines Rank Reversals (1) or Rank Reversals (2) are as far away as possible from the origin in these figures. This will make more stable and reliable the AHP.

Three causes attributable to the construction of $\mathbf{G}_{A x C}$ and $\mathbf{B}_{C \times 1}$ can negatively impact the rank reversal. First, inclusion or removal of criteria and/or alternatives. Second, uncertainties or inaccuracies in $\mathbf{G}_{A x C}$ and/or $\mathbf{B}_{C \times 1}$ combined with "ill-conditioned" $\mathbf{G}_{A x C}$. Third, deficient or almost deficient rank of $\mathbf{G}_{A x C}$. These three causes are linked to two properties of $\mathbf{G}_{A x C}$ : rank deficient and "ill-conditioned" matrix, which in turn is related to the problem being mathematically "wellposed" and "well-conditioned" (Alvarez et al. 2021).

In the first cause the dimension of $\mathbf{G}_{A x C}$ is changed, and consequently its properties of rank and condition number. Geometrically, if an alternative is included/removed, the vector subspace $S \subseteq \mathbb{R}^{A}$ will have its dimension changed to greater or lesser, and if a criterion is included/removed the number of hyperplanes will be changed to greater or lesser (Alvarez et al. 2021). Therefore, in both cases of inclusion/removal, the point common to all hyperplanes (solution) will be changed.

In the second cause the dimension of $\mathbf{G}_{A \times C}$ is not changed. However, if $\mathbf{G}_{A x C}$ is "illconditioned", small changes in $\mathbf{G}_{A x C}$ and/or $\mathbf{B}_{C \times 1}$ due to uncertainties or inaccuracies generate large changes in the solution. Among these large changes in the solution is included the rank reversal.

In the third cause, there can be infinite solutions in the equivalent formulation of AHP. Consequently, the solution of the original formulation can change between the infinites of the equivalent formulation, motivated by small perturbations in $\mathbf{G}_{A \times C}$ and/or $\mathbf{B}_{C \times 1}$. These infinite solutions include those with a rank reversal. 


\section{Conclusions}

In this work the theoretical developments carried out in (Alvarez et al. 2021) are verified in 22 applications of AHP. The results show that the last step of the method, Synthesis, can be reformulated in terms of a linear system of equations. In all application cases the solution $\mathbf{X}_{A \times 1}^{E Q V 1}$ $=\mathbf{X}_{A \times 1}^{E Q V 2}=\mathbf{X}_{A \times 1}^{E Q V 3}=\mathbf{X}_{A \times 1}^{O R G}$. Moreover, the two formulations of the AHP show similar behavior in the sensitivity analysis performed.

A sensitivity analysis was carried out, considered standard in the context of the AHP, where the critical elements of $\mathbf{G}_{A x C}$ and $\mathbf{B}_{C \times 1}$ are determined by perturbations in relative and absolute terms. It was found that there is no simple relationship between the critical element and the perturbation used, although a tendency for the critical criterion to be the criterion of greater or lesser weight can be noticed depending on whether the perturbation is relative or absolute.

A sensitivity analysis different from the standard was performed, where the critical column vector of $\mathbf{G}_{A x C}$ is determined. A stochastic method was developed to randomly perturb all components of the column vectors. It was found that the column of the critical element does not necessarily coincide with the column of the critical column vector. Moreover, in some applications considering the same amount of perturbation measured by the matrix norm, the rank reversal occurs first with the perturbation of the critical column vector than with the perturbation of the critical element. This also occurs when all components of the vector $\mathbf{B}_{C \times 1}$ are randomly perturbed. Therefore, in these cases, AHP is more sensitive to perturbations in the critical column vector than to perturbations in the critical element. Furthermore, the critical column vector is unique independently of whether the perturbation is relative or absolute.

A new sensitivity analysis was performed via condition number of $\mathbf{G}_{A \times C}$, where perturbations are made in the input data $\mathbf{G}_{A x C}$ or $\mathbf{B}_{C \times 1}$ to calculate the relative error $\frac{\left\|\Delta \mathbf{G}_{A x C}\right\| m}{\left\|\mathbf{G}_{A x C}\right\| m}$ or $\frac{\left\|\Delta \mathbf{B}_{C \times 1}\right\| m}{\left\|\mathbf{B}_{C \times 1}\right\| m}$. Subsequently, the curves that determine the impact of these perturbations on the relative error of the solution for the two formulations are plotted. It was found that the curves of the two formulations are similar straight lines. Moreover, the rank reversal effect corresponds to a region bounded inferiorly by the vertical line Rank Reversals (1) or Rank Reversals (2) and superiorly by the vertical line Bound of infeasible. This region will always exist for any linear system of equations. Therefore, in all AHP applications of the type determined by equation (1), the rank reversal effect will always be present.

An example of application of AHP showed how the algebraic transformations described in (Alvarez et al. 2021) allow to make a rank deficient matrix in full rank, and in this way the condensed formulation presents greater stability and reliability. Finally, it must be said that the mathematical developments carried out here can be applied to other decision-making methods based on matrices and linear systems of equations. In addition, in future work it is necessary to go even deeper into the theoretical analysis initiated in (Alvarez et al. 2021).

\section{Acknowledgements}

This work was supported by the CAPES and UFF. This paper is dedicated to the Memory of Professor Thomas L. Saaty (1926-2017).

\section{References}

Aires R.F.d.F. \& Ferreira L. (2018) The Rank Reversal Problem in Multi-Criteria Decision Making: A Literature Review. Pesquisa Operacional, 38(2): 331-362. https://doi.org/10.1590/0101-7438.2018.038.02.0331

Al-Harbi K.M.A.S. (2001) Application of the AHP in project management. International Journal of Project Management, 19(1): 19-27. https://doi.org/10.1016/S0263-7863(99)00038-1 
Alvarez G.B., de Almeida R.G., Hernández C.T. \& de Sousa P.A.P. (2021) Some mathematical comments about the Analytic Hierarchy Process: Part I - Theoretical analysis. Journal of Multi-Criteria Decision Analysis, 21: 1-15. https://doi.org/10.1002/mcda.1762

Alves J.R.X. \& Alves J.M. (2015) Definição de localidade para instalação industrial com o apoio do método de análise hierárquica (AHP). Production Journal, 25(1): 13-26. https://doi.org/10.1590/S0103-65132014005000023

Belton V. \& Gear T. (1983) On a shortcoming of Saaty's method of analytic hierarchies. Omega, 11(3): 228-230. https://doi.org/10.1016/0305-0483(83)90047-6

Benítez J., Carpitella S., Certa A. \& Izquierdo J. (2019) Characterization of the consistente completion of Analytic Hierarchy Process comparison matrices using graph theory. Journal of Multi-Criteria Decision Analysis, 26(1-2): 3-15. https://doi.org/10.1002/mcda.1652

Cabała P. (2010) Using the Analytic Hierarchy Process in evaluating decision alternatives. Operations Research and Decisions, 20(1): 5-23.

Chalúpková E. \& Franek J. (2014) Application of the Analytic Hierarchy Process method in a comparison of financial leasing and loans. Ekonomická revue - Central European Review of Economic Issues, 17: 75-84. https://doi.org/10.7327/cerei.2014.06.03

Damdinsuren M. \& Ishdamba B. (2017) Application of the AHP in Choosing Project Manager. International Journal of English Literature and Social Sciences, 2(4): 155-160. https://dx.doi.org/10.24001/ijels.2.4.19

de Abreu L.M., Granemann S.R., Gartner I. \& Bernardes R.S. (2000) Escolha de um programa de controle da qualidade da água para consumo humano aplicação do método AHP. Revista Brasileira de Engenharia Agrícola e Ambiental, 4(2): 257-262.

de Almeida R.G. (2019) Uma análise do processo de agregação aditiva de resultados do método Analytic Hierarchy Process baseada em Sistemas de Equações Lineares. Dissertação (Programa de Pós-Graduação em Modelagem Computacional em Ciência e Tecnologia). Universidade Federal Fluminense, Volta Redonda, Brasil.

Demmel J.W. (1997) Applied numerical linear algebra. Volume 56. Philadelphia: SIAM. 430 p.

de Paula J.O. \& Mello C.H.P. (2013) Seleção de um modelo de referência de PDP para uma empresa de autopeças através de um método de auxílio à decisão por múltiplos critérios. Production, 23(1): 144-156. http://dx.doi.org/10.1590/S0103-65132012005000082

dos Anjos Bainha F.S., Vianna D.S. \& Meza E.B.M. (2018) Aplicação do Método AHP à Tomada de Decisão Gerencial: um estudo de caso em serviço de hotelaria offshore. Marketing \& Tourism Review, 3(2): 1-40. https://doi.org/10.29149/mtr.v3i2.4334

Franco M.M., Monegat A.D.R., Lima D.d. \& Corso L.L. (2017) Aplicação do método AHP na tomada de decisão do processo de terceirização de componentes usinados em uma empresa multinacional (p. 1-17). In: XXXVII Encontro Nacional de Engenharia de Produção, Joinville, Brasil.

Gentle J.E. (2007) Matrix Algebra. Volume 10. New York: Springer. 530 p.

Giri S. \& Nejadhashemi A.P. (2014) Application of Analytical Hierarchy Process for effective selection of agricultural best management practices. Journal of Environmental Management, 132: 165-177. https://doi.org/10.1016/j.jenvman.2013.10.021

Golub G.H. \& Van Loan C. (2013) Matrix computations. $4^{\circ}$ edition. Baltimore: The Johns Hopkins University Press. 756 p.

Gomede E. \& Barros R. (2012) Utilizando o método Analytic Hierarchy Process (AHP) para priorização de serviços de TI: Um estudo de caso (p. 408-419). In: VIII Simpósio Brasileiro de Sistemas de Informação, São Paulo, Brasil.

Koksal C.D. \& Ozmutaf N.M. (2009) Using Analytic Hierarchy Process for selecting the appropriate host country to study english language abroad. International Journal of Social Sciences and Humanity Studies, 1(1): 37-46.

Lee D.Q. (2012) Numerically efficient methods for solving least squares problems. Available in: https://www.math.uchicago.edu/ may/REU2012/REUPapers/Lee.pdf. 
Lucena A.F.E. \& Mori L.M.d. (2018) Uso do Analytic Hierarchy Process (AHP) para Hierarquização de Métodos de Mensuração do Grau de Aplicação da Construção Enxuta. Revista Gestão Industrial, 14(4): 48-69.

Maleki H. \& Zahir S. (2013) A comprehensive literature review of the rank reversal phenomenon in the Analytic Hierarchy Process. Journal of Multi-Criteria Decision Analysis, 20(3-4): 141155. https://doi.org/10.1002/mcda.1479

Mendes F.d.S., Bastos M.H.R., de Rezende Souza T.C. \& Hernandez C.T. (2014) Utilização da Metodologia Analytic Hierarchy Process (AHP) na Mensuração da Importância das Características Empreendedoras - um Estudo em um Curso de Engenharias de Volta Redonda (p. 1-11). In: XI Simpósio de Excelência em Gestão e Tecnologia. Resende, Brasil.

Moler C.B. (2008) Numerical Computing with MATLAB. Volume 87. Philadelphia: SIAM. 347 p.

Oliveira A.A.M. (2013) Método AHP como optimização na seleção de fornecedores numa empresa de materiais de construção. Dissertação (Programa de Pós-Graduação em Engenharia Electrotécnica e de Computadores). Instituto Superior de Engenharia do Porto, Departamento de Engenharia Electrotécnica, Porto, Portugal.

Pankratova N. \& Nedashkovskaya N. (2016) Sensitivity analysis of a decision-making problem using the Analytic Hierarchy Process. International Journal Information Theories and Applications, 23(3): 232-251.

Quarteroni A. \& Saleri F.E. (2007) Cálculo Científico com MATLAB e Octave. Milano: Springer. $320 \mathrm{p}$.

Sbeity I., Dbouk M. \& Kobeissi H. (2014) Combining the Analytical Hierarchy Process and the genetic algorithm to solve the timetable problem. International Journal of Software Engineering \& Applications, 5(4): 39-50. https://doi.org/10.5121/ijsea.2014.5403

Schmidt Â.M.A. (1995) Processo de apoio à tomada de decisão abordagens: AHP e MACBETH. Dissertação (Programa de Pós-Graduação em Engenharia de Produção). Universidade Federal de Santa Catarina, Departamento de Engenharia de Produção e Sistemas, Florianópolis, Brasil.

Shahroodi K., Amin K., Shabnam A., Elnaz S. \& Najibzadeh M. (2012) Application of Analytical Hierarchy Process (AHP) technique to evaluate and selecting suppliers in an effective supply chain. Kuwait Chapter of Arabian Journal of Business and Management Review, 33(835): 114.

Strang G. (1988) Linear Algebra and Its Application. $3^{\circ}$ edition. Philadelphia: Harcourt. 505 p.

Su S.W., Xiong W., Ren Q.L., Li B. \& Sun W.J. (2014) The Application of Analytic Hierarchy Process (AHP) in the Power Grid Planning. Advanced Materials Research, 860: 2540-2543. https://doi.org/10.4028/www.scientific.net/AMR.860-863.2540

Trevizano W.A. \& Freitas A.L.P. (2005) Emprego do Método da Análise Hierárquica (A.H.P.) na seleção de processadores (p. 2972-2979). In: XXV Encontro Nacional de Engenharia de Produção, Porto Alegre, Brasil.

Triantaphyllou E. \& Sánchez A. (1997) A sensitivity analysis approach for some deterministic multi-criteria decision-making methods. Decision Sciences, 28(1): 151-194. https://doi.org/10.1111/j.1540-5915.1997.tb01306.x

Wollmann D., Steiner M.T.A., Vieira G.E. \& Steiner P.A. (2012) Avaliação de operadoras de saúde por usuários pelo método Analytic Hierarchy Process. Revista de Saúde Pública, 46: 777-783. https://doi.org/10.1590/S0034-89102012000500003

Yang W.Y., Cao W., Chung T.S. \& Morris J. (2005) Applied numerical methods using MATLAB. New Jersey: John Wiley \& Sons. 509 p. 